\title{
The impact of cross-language phonological overlap on bilingual and monolingual toddlers' word recognition*
}

\author{
KATIE VON HOLZEN \\ Department of Hearing and Speech Sciences, University of \\ Maryland, USA \\ Laboratoire Psychologie de la Perception, Université Paris \\ Descartes, France \\ Psychology of Language Research Group, \\ Georg-August-Universität Göttingen, Germany \\ CHRISTOPHER T. FENNELL \\ School of Psychology and the Department of Linguistics, \\ University of Ottawa, Canada \\ NIVEDITA MANI \\ Psychology of Language Research Group, \\ Georg-August-Universität Göttingen, Germany
}

(Received: August 03, 2016; final revision received: April 4, 2018; accepted: April 19, 2018; first published online 4 June 2018)

We examined how L2 exposure early in life modulates toddler word recognition by comparing German-English bilingual and German monolingual toddlers' recognition of words that overlapped to differing degrees, measured by number of phonological features changed, between English and German (e.g., identical, 1-feature change, 2-feature change, 3-feature change, no overlap). Recognition in English was modulated by language background (bilinguals vs. monolinguals) and by the amount of phonological overlap that English words shared with their L1 German translations. L1 word recognition remained unchanged across conditions between monolingual and bilingual toddlers, showing no effect of learning an L2 on L1 word recognition in bilingual toddlers. Furthermore, bilingual toddlers who had a later age of L2 acquisition had better recognition of words in English than those toddlers who acquired English at an earlier age. The results suggest an important role for $L 1$ phonological experience on L2 word recognition in early bilingual word recognition.

Keywords: bilingual development, phonological acquisition, cognate word recognition

For developmental researchers, bilingualism allows for an investigation of how the acquisition of two complete language systems can impact language acquisition. It is important to note, however, that bilingual acquisition can occur at various points in development (e.g., children introduced to a second language in school, adults moving to a new country where their native language is not the dominant language, etc.). We focus on a special instance of bilingualism: exposure to a second language in a bilingual (German-English) preschool during early language acquisition. Specifically, we investigate how exposure to a second language impacts familiar word recognition in bilingual toddlers' first (L1) and second

\footnotetext{
* This work was funded by the German Initiative of Excellence (Institutional Strategy). During data analyses and manuscript preparation, the first author was additionally funded by an ANR-13BSH2-0004 grant and by training grant DC-00046 from the National Institute of Deafness and Communicative Disorders of the National Institutes of Health. The authors would like to acknowledge Sandrien Van Ommen and Cory Bonn for helpful discussions of model structure and interpretation. The authors thank the preschool staff members for their assistance, especially in testing. A special thank you is directed to all of the toddlers and their parents who participated in this study.
}

(L2) languages, especially when the words share varying degrees of phonological overlap across those languages.

Exposure to a second language in a preschool setting can impact lexical access in preschool-age toddlers, including automatic translation of L2 words to their L1 translation equivalents and cross-language phonological priming where words from one language prime recognition of similar-sounding words in the other language (Von Holzen \& Mani, 2012). This crosslanguage priming is similar to the within-language phonological priming demonstrated in monolingual toddlers (e.g., Mani \& Plunkett, 2008, 2011b). Monolingual infants encode their lexical representations with fine phonetic detail (Mani \& Plunkett, 2010, 2011a; White \& Morgan, 2008), but this ability is in place after many months of exposure to their native language. The toddlers in our study have been exposed to their native language their entire life, while exposure to their second language came later in life. These varying levels of experience may differentially affect representations of words from their first and second language. Furthermore, these toddlers are confronted with a new language and set of words, consisting of phonemes that are both similar

Address for correspondence:

Dr. Katie Von Holzen, Department of Hearing and Speech Sciences, University of Maryland, Samuel J. LeFrak Hall, 7251 Preinkert Dr., College Park, MD 20742

katie.m.vonholzen@gmail.com 
and different to the phonemes in words from their first, more familiar, language. To navigate through this new linguistic environment, these toddlers need to be able to engage their existing phonological knowledge, but also be flexible enough to learn words from their new language that deviate from their L1 phonological representations.

One special type of word, cognates, presents an interesting case for the young L2 learner. Cognates are words that overlap in form and meaning across two languages, i.e., translation equivalents overlapping in phonology and/or orthography across the two languages of a bilingual (e.g., English - fort /fo:t/, Dutch fort /fort/; Dijkstra, Grainger \& van Heuven, 1999). Numerous studies demonstrate that adult bilinguals typically recognize cognate words faster than non-cognate words (Blumenfeld \& Marian, 2007; Dijkstra et al., 1999; Dijkstra, Miwa, Brummelhuis, Sappelli \& Baayen, 2010; Schwartz, Kroll \& Diaz, 2007), known as the COGNATE FACILITATION EFFECT. Form overlap between cognate words may lead to simultaneous activation of the labels from both languages, resulting in speeded form activation and consequently faster recognition of cognate words. The phonological similarity of cognate words has been found to facilitate recognition in children as young as 5- to 8years (Brenders, van Hell \& Dijkstra, 2011; Poarch \& van Hell, 2012). In the current study, we explore whether the overlapping phonology of cognate words facilitates their recognition in even younger bilinguals (i.e., toddlers), and whether the degree of phonological similarity between L1 and L2 for cognate words modulates this recognition.

For the young L2 learner, the presence of phonologically similar words in the new language may facilitate L2 acquisition and recognition, due to the phonological overlap and shared meaning with their known L1 counterparts. Imagine a German toddler who is now consistently exposed to English. They know the word "Bett" (bed), but find themselves in a situation where this familiar object is being labeled "bed". The overlap between the two words may be facilitatory, such that the learning and subsequent recognition of the English "bed" may proceed relatively smoothly. Indeed, in monolinguals, familiarity with similar sounding words has been found to facilitate word segmentation (Altvater-Mackensen \& Mani, 2013) and novel words may be more readily learned when they come from the same neighborhood as words already known by toddlers (Newman, Samuelson \& Gupta, 2008; see also Storkel, 2004). Furthermore, evidence in both monolingual (Arias-Trejo \& Plunkett, 2009) and bilingual (Singh, 2014) toddlers suggests that semantic links between words can facilitate their recognition. Evidence from both semantic priming (Singh, 2014) and word processing speed (DeAnda, Hendrickson, Zesiger, Poulin-Dubois \& Friend, 2017) suggest that the more dominant L1 of bilingual toddlers, supports processing of the non-dominant L2. We may therefore observe improved word recognition when phonological and semantic similarities across the languages of the bilingual toddler (e.g., from L1 to L2) are combined, as is the case for cognate words. Cognate words occur more frequently than non-cognate words in the early bilingual toddler lexicon (Bosch \& Ramon-Casas, 2014; Schelletter, 2002), which suggests that these words may be more readily learned and their recognition more robust than labels not sharing form similarity between languages.

Alternatively, the similarity between words across languages may impede their acquisition and subsequent recognition. Some studies with adult bilinguals have found that recognition of cognate words is poorer than that of non-cognate words (Dijkstra et al., 1999, 2010; Schwartz et al., 2007). Instead of facilitation, the two formsimilar labels compete for activation, resulting in delayed recognition of cognate words. Indeed, monolinguals' knowledge of phonologically similar words can also lead to increased competition and subsequent interference in recognition of similar-sounding words, albeit with different meanings (Mani \& Plunkett, 2011b; Swingley \& Aslin, 2007). Extending this to the young L2 learner, the competition between phonologically similar words may result in no benefit, and potentially interference between the two representations. This may be particularly exacerbated in young bilingual learners who may have more robust lexical representations in their more dominant L1, based on greater experience, compared to less established L2 representations of words. Although the L1 does support processing of the L2 in bilingual toddlers (DeAnda et al., 2017; Singh, 2014), this relationship may ultimately impede L2 word recognition in cases of high lexical competition.

Further, complete phonological overlap between words across languages rarely occurs (Dijkstra et al., 1999) and these small phonological variations across the two languages may impede word recognition in the young L2 learner. Indeed, evidence from monolingual, and recently bilingual, infants suggests that young children are particularly sensitive to even small changes to the phonological form of words (Ballem \& Plunkett, 2005; Swingley \& Aslin, 2000; Wewalaarachchi, Wong \& Singh, 2017). When tested on the same set of stimuli, monolingual Mandarin and bilingual Mandarin-English children show similar sensitivity to consonant, vowel, and tone mispronunciations (Wewalaarachchi et al., 2017). Furthermore, the size of the phonological variation, as measured by number of phonological features changed, also impacts word recognition. White and Morgan (2008) tested 19-month-old infants' sensitivity to 1-, 2-, and 3-feature consonant mispronunciations of familiar object names (for vowels see Mani \& Plunkett, 2011a). Although infants continued to fixate the familiar object upon hearing a 1-feature mispronunciation of the label for this object, they looked less to the target 
upon hearing these small mispronunciations than when hearing correct pronunciations, suggesting sensitivity to the mispronunciation. Furthermore, 2- and 3-feature phonological changes led to decreasing target looks, suggesting a graded sensitivity to mispronunciations. These studies suggest that even when a mispronounced label shares significant overlap with a familiar label, infants are sensitive to this difference and do not accept the mispronounced label as correct (Mani \& Plunkett, 2011a; White \& Morgan, 2008). In word recognition, bilingual toddlers may be sensitive to the subtle differences between languages for labels and may potentially regard the newly learned L2 label as a deviant pronunciation of the L1 token, leading to interference in recognition of the L2 token.

One series of experiments has specifically investigated the level of phonological detail present in bilingual toddlers' representations of cognate words. RamonCasas and colleagues tested Spanish-Catalan bilingual and Spanish/Catalan monolingual toddlers on their ability to detect a phonological alternation present in cognate (Ramon-Casas, Swingley, Sebastian-Gallés \& Bosch, 2009) and non-cognate (Ramon-Casas \& Bosch, 2010) words. Critically, the alteration was a vowel contrast that only occurs in Catalan. When tested on cognate words, monolingual Catalan 2-year-olds and older bilingual toddlers (3.5-years-of-age) were sensitive to the change. Bilingual Spanish-Catalan two-year olds, however, were unable to detect the vowel change in cognate words, but were successful when tested on non-cognate words (Ramon-Casas \& Bosch, 2010). It appears, therefore, that the similarity of words across languages (cognate vs. non-cognate) as well as the amount of language experience (2- vs. 3.5-year-olds) affect the level of phonetic detail bilingual toddlers represent in familiar words. Ramon-Casas, Bosch, and colleagues conclude that the lack of sensitivity to a vowel change in cognate words is due to interference between the slightly differing word form representations in the bilinguals' two languages. This phonological and allophonic competition between the two cognate words may lead to less specific phonological representations of each word. Bilingual toddlers may, therefore, have more phonologically specified representations for non-cognate words compared to cognate words, at least until they have gathered more language experience.

This relates to two important concepts in early phonological development, namely PHONOLOGICAL DISTINCTIVENESS and PHONOLOGICAL CONSTANCY (see Best, Tyler, Gooding, Orlando \& Quann, 2009). The former, PHONOLOGICAL DISTINCTIVENESS has already been highlighted in our discussion of mispronunciation studies: if a word is changed in a way that no longer preserves the critical phonological structure, this interferes with the ability to recognize the word as an acceptable label. When presented with a mispronunciation of a familiar word, infants and toddlers may show recognition (e.g., 1-feature mispronunciations), although this is diminished in comparison to that of the correct pronunciation of the word. If bilingual toddlers treat an L2 label as a deviant pronunciation of the cognate L1 label, they may similarly demonstrate reduced recognition of the L2 label in comparison to the L1 one.

Phonological constancy is the ability to accept phonological variation across different instances of a word, when it does not compromise the overall identity of the word (e.g., different speakers, accented speech). At 19-months, infants have been found to properly apply the principles of both phonological distinctiveness and constancy, accepting both native and non-native accented labels for familiar objects, although 15-month-olds only showed recognition for objects labeled in their native accent (Best et al., 2009; Mulak, Best \& Tyler, 2013; see Schmale, Hollich \& Seidl, 2011 for evidence from word learning). Thus, even monolingual children appear to require increased language experience before accepting small variations as acceptable pronunciations of a word, suggesting that the phonological overlap of labels between languages may be less of a benefit for toddlers learning a second language and may potentially cause more interference in word recognition.

The nature of bilingual lexical processing provides a third concept beyond phonological distinctiveness and constancy that bilingual toddlers must contend with: language non-selective lexical access. Mounting evidence suggests that when processing one language, bilingual adults simultaneously activate the other language (for a review see Dijkstra, 2005); their lexical access is language non-selective. This has also been extended to bilingual toddlers, finding evidence that upon hearing an L2 word, its L1 translation is also activated (Von Holzen \& Mani, 2012). According to the Revised Hierarchical Model (Kroll \& Stewart, 1994; Kroll, van Hell, Tokowicz \& Green, 2010), lexical access to the L2 proceeds through mediation via its L1 translation equivalent until the individual has gathered enough skill in their L2 to directly access meaning. In bilingual adults, the cognate facilitation effect in picture naming of cognate words is greater for L2 compared to L1, due to the boosted activation the $\mathrm{L} 2$ form receives from its L1 translation equivalent. Recently, non-selective lexical access was proposed as a bootstrapping mechanism for L2 learning in young language learners (Mallikarjun, Newman \& Novick, 2017). For bilingual toddlers, this could mean better recognition for L2 cognate words that are highly similar in L1 and L2, due to simultaneous activation of the L1 and L2. For cognate words that are less similar between languages, however, simultaneous activation may interfere with word recognition, as the two word forms are similar enough that the L1 word interferes with the 
L2 word. Whether resulting in word recognition that is facilitated (in the case of highly similar L1-L2 cognate words) or hindered (in the case of less similar L1-L2 cognate words), we can expect that the effects would be more prominent in the L2 of bilingual toddlers than their L1.

Against this background, we investigated the extent to which the degree of phonological overlap and differences between labels impacts bilingual and monolingual toddlers' recognition of familiar words. The bilingual toddlers tested in the current study were exposed to German and English while attending preschool, and heard German in their home. Floccia and colleagues (Floccia et al., 2018) recently quantified the average phonological overlap for English words on the Oxford CDI (Hamilton, Plunkett \& Schafer, 2000) and 13 other languages, including German. The average phonological overlap, based on Levenshtein distance, for English-German words was $20 \%$, placing it as the $3^{\text {rd }}$ most overlapping language with English. Indeed, greater phonological overlap between languages predicted measured vocabulary, suggesting that toddlers exposed to languages such as German and English benefit from this general overlap. In this study, we are investigating how exact this overlap needs to be at the lexical level to invoke potential enhancements in lexical recognition.

In previous studies, monolingual toddlers have shown graded sensitivity to the number of features changed from the target label: recognition decreases as the number of altered phonological features increases (Mani \& Plunkett, 2011a; White \& Morgan, 2008). We likewise test toddlers on words that differ from one another in their similarity, indexed by the number of phonological features changed (see Table 1), but this similarity is between the languages of the child. Importantly, these words are not mispronunciations, but instead real English and German words that differ in the number of phonological features changed between labels. For example, the word bed has a one-feature change of voicing between English (/bed/) and German (/bet/), while the word fish has no phonological alterations between English and German (/fi $\mathrm{J} /$ ). In addition to the above types, we test toddlers on their recognition of words that differ by 2 (glass: English /glæs/ - German /glas/, backness and tenseness) and 3 (bus: English $/ \mathrm{b}_{\Lambda \mathrm{s}} /$ - German /bus/, height, backness, roundness) features, as well as words that share no overlap between languages (bird: English /b and d/ - Vogel: German /fo:gl/).

When tested in English, German monolingual toddlers should treat English words that have phonological overlap with their known German words as mispronunciations of these words. As a reminder, monolingual toddlers do demonstrate recognition of 1-feature changes, although this recognition is reduced from correct pronunciations (White \& Morgan, 2008). We predict a similar pattern of results in our sample of monolingual toddlers: recognition of both identical and 1-feature changes, but as the number of feature changes increases, we expect recognition to decrease. For bilingual toddlers, experience learning English may result in tolerance for small phonological changes between languages and therefore recognition patterns may not differ between identical and 1-feature change words. Regarding words with more feature changes (i.e., 2 or 3 ) or no overlap between languages, if L2 English word recognition is influenced by L1 German phonological knowledge, then these words may be treated as mispronunciations of L1 words such that toddlers may show decreased recognition or outright rejection of these words, despite their similarity between languages. Alternatively, if these early L2 learners have started to acquire knowledge of their L2 phonology and use this selectively in L2 word recognition, they should treat these words as acceptable labels when presented in their L2.

When tested in German, monolingual toddlers should show recognition of all words, as overlap with English, an unknown language, should have no influence. For bilingual toddlers, however, an increase or decrease in word recognition indicates the influence of learning a second language. For example, for words with greater overlap between languages, an increase in recognition relative to monolingual toddlers would indicate that the phonological overlap between languages facilitates recognition. A decrease, in contrast, would indicate that knowledge of phonological similar words interferes with recognition. Thus, the bilingual case in a German lexical context provides a test of the influence of L2 acquisition on native-language phonology.

\section{Methods}

\section{Participants}

Bilingual toddlers were recruited from a local bilingual preschool located in a small city in central Germany (final sample $n=31$ ). Toddlers were on average 36.49 months $\left(S D=9.01\right.$, range 18 to 53 months $\left.^{1}\right)$ in the preschool for 16.39 months $(S D=6.43$ months, range $=5-23$ months) and their age of acquisition (AoA) for English was on average 20.11 months $(S D=6.65$ months, range $=11-35$ months). Attendance at this preschool was open to the public and not part of a special early education program to promote bilingualism. An additional 7 toddlers were tested but not included in the

1 It should be noted that the age range is considerably larger compared to typical IPL studies. However, ensuring that all of the toddlers experienced the same bilingual environment was viewed as a greater advantage than testing toddlers of a very similar age (see also Von Holzen \& Mani, 2012). 
final analysis due to additional exposure to English at home.

Toddlers from this particular preschool received an equivalent amount of instruction in both English and German during their time at the preschool (6-8 hours per day, approximately 3-4 hours per language). This method of instruction, called an "enrichment program" (Rohde, 2001), provides an ideal setting for studying bilingual toddlers since all children receive a similar amount of daily L2 English exposure. Preschool teachers carefully manage bilingual instruction, such that the teachers address the toddlers using one language consistently and never the other. Teachers were either native German speakers and addressed children in either German or English, or were native English speakers and addressed children in English (non-native English exposure will be addressed in the Limitations section). This is styled after the "One Parent, One Language" theory (Bain \& Yu, 1980; Ronjat, 1913) and is applied in many preschools (Genesee, 2010; Rohde, 2001). Exposure to L2 English began after 11-months-ofage and our sample was therefore sequentially bilingual. We considered German to be their L1 and English their L2 based on the home and community contexts of the sample. Similar to Von Holzen and Mani (2012), we were unable to gather accurate vocabulary questionnaire information about the words these toddlers knew in either German or English. In particular, their English vocabulary knowledge could only be rated by their English teachers, who would have difficulties determining what individual words each individual child comprehended, as they were caring for many children simultaneously. We note, however, that when testing a similar population of bilingual toddlers on words comparable to those in the current study, those toddlers recognized non-cognate stimuli from both English and German (Von Holzen \& Mani, 2012, p. 576-577). Thus, these children should comprehend most, if not all, of the simple words used in the study (see stimuli section below for further evidence that children should know our target words by 18 months).

Monolingual toddlers $(n=23,10$ females) were recruited from the same city as the bilingual toddlers. Average age was 35.67 months $(S D=6.40, M d n=$ 35.33 , range 23 to 47 months). The age range of monolingual toddlers was large in order to provide a better comparison to the large age range of our bilingual sample. Monolingual toddlers had no exposure to English or any other languages and we considered German to be their L1.

\section{Stimuli}

We selected 15 German-English word pairs familiar to 18-month-olds in English according to the Oxford Communicative Development Inventory (OCDI, Hamilton et al., 2000) and German according to its
German equivalent, the Fragebogen zur Frühkindlichen Sprachentwicklung (FRAKIS, Szagun, Stumper \& Schramm, 2009). The non-cognate word "bread" (Brot) was removed from the final analysis, due to onset overlap between languages (/br/), leaving 14 GermanEnglish word pairs. German-English word pairs were assigned to conditions as either a) identical, b) 1-feature changes, c) 2-feature changes, d) 3-feature changes, or e) had no overlap. A regression analysis on the percentage of children producing each item at 18 months for both German (Szagun et al., 2009) and English (Floccia, 2017) revealed no significant difference in production between languages or conditions. Due to the limited number of available English-German word pairs with overlapping phonology, we included both vowel and consonant changes. See Table 1 for a full list of stimuli, IPA transcriptions, differing phonological features, as well as target-distractor pairings and gender-markings.

Visual stimuli were prototypical photographs of the target words on a gray background. In addition, a further set of images served as yoked distracters for each target image across both language versions of the experiment. Target-distracter pairs shared the same gender-marking (German stimuli) and there was no phonological or semantic relationship between them. An (American) English-German bilingual female speaker, who learned both languages from birth, recorded the stimuli using infant-directed speech. Target words were recorded with a carrier phrase in German for the German version of the experiment (Wo ist der/die/das X) and in English for the English version of the experiment (Where is the $X)$.

\section{Experimental design}

Half of the toddlers were tested first on the German version of the experiment, and half were tested first on the English version of the experiment. For each language version of the experiment, the toddler saw 15 trials, consisting of two identical, two 1-feature, two 2-feature, four 3-feature, and five no overlap word trials (bread Brot was later removed). Stimuli were presented using the Look software (Meints \& Woodford, 2008). Each trial began with simultaneous presentation of a target and distractor image. The onset of the carrier phrase, containing the target word, was timed such that the onset of the target label was always at $2500 \mathrm{~ms}$. The target and distracter images remained on-screen for the total duration of the trial: $5240 \mathrm{~ms}$. Figure 1 presents a schematic of an individual trial design. Target image side was randomized, with no bias towards the target appearing to the left or to the right of the screen. Presentation of trials was randomized. Trials began only once the child fixated the screen in front of them. 
Table 1. Summary of target stimuli, their International Phonetic Alphabet transcriptions, and distractor pairings.

\begin{tabular}{|c|c|c|c|c|c|c|c|}
\hline \multicolumn{6}{|c|}{ Target } & \multirow{2}{*}{\multicolumn{2}{|c|}{ Distractor }} \\
\hline & \multicolumn{2}{|c|}{ English } & \multicolumn{2}{|c|}{ German } & \multirow[b]{2}{*}{ Features differed } & & \\
\hline & & IPA & & IPA & & English & German \\
\hline \multicolumn{8}{|l|}{ identical } \\
\hline & clown & /klaun/ & der Clown & /klaon/ & - & cake & der Kuchen \\
\hline & fish & $/ \mathrm{frj} /$ & der Fisch & $/ \mathrm{fij} /$ & - & lion & der Löwe \\
\hline \multicolumn{8}{|c|}{ 1-feature } \\
\hline change & $\begin{array}{l}\text { bed } \\
\text { baby }\end{array}$ & $\begin{array}{l}\text { /bed/ } \\
/ \text { 'berbi// }\end{array}$ & $\begin{array}{l}\text { das Bett } \\
\text { das Baby }\end{array}$ & $\begin{array}{l}\text { /bet/ } \\
\text { /be:bi// }\end{array}$ & $\begin{array}{l}\text { voicing } \\
\text { height }\end{array}$ & $\begin{array}{l}\text { water } \\
\text { telephone }\end{array}$ & $\begin{array}{l}\text { das Wasser } \\
\text { das Telefone }\end{array}$ \\
\hline \multicolumn{8}{|c|}{ 2-feature } \\
\hline change & $\begin{array}{l}\text { glass } \\
\text { toast }\end{array}$ & $\begin{array}{l}\text { /glæs/ } \\
\text { /toust/ }\end{array}$ & $\begin{array}{l}\text { der Glas } \\
\text { der Toast }\end{array}$ & $\begin{array}{l}\text { /glas/ } \\
\text { /to:st/ }\end{array}$ & $\begin{array}{l}\text { backness, tenseness } \\
\text { backness, height }\end{array}$ & $\begin{array}{l}\text { bicycle } \\
\text { broom }\end{array}$ & $\begin{array}{l}\text { der Fahrrad } \\
\text { der Besen }\end{array}$ \\
\hline \multicolumn{8}{|l|}{ 3-feature } \\
\hline change & $\begin{array}{l}\text { ball } \\
\text { bus } \\
\text { puzzle } \\
\text { tiger }\end{array}$ & $\begin{array}{l}/ \mathrm{b} \supset \mathrm{l} / \\
/ \mathrm{b} \Lambda \mathrm{s} / \\
/ \mathrm{p} \Lambda \mathrm{zl} / \\
/ / \operatorname{tatg} /\end{array}$ & $\begin{array}{l}\text { der Ball } \\
\text { der Bus } \\
\text { das Puzzle } \\
\text { der Tiger }\end{array}$ & $\begin{array}{l}\text { /bal/ } \\
\text { /bus/ } \\
\text { /puzl/ } \\
\text { /ti:ge/ }\end{array}$ & $\begin{array}{l}\text { backness, height, roundness } \\
\text { backness, height, roundness } \\
\text { backness, height, roundness } \\
\text { backness, height + height }\end{array}$ & $\begin{array}{l}\text { apple } \\
\text { spoon } \\
\text { car } \\
\text { monkey }\end{array}$ & $\begin{array}{l}\text { der Apfel } \\
\text { der Löffel } \\
\text { das Auto } \\
\text { der Affe }\end{array}$ \\
\hline \multicolumn{8}{|c|}{ no overlap } \\
\hline & bird & $/ \mathrm{b}^{2} \mathrm{~d} /$ & der Vogel & /fo:gl/ & - & bear & der Bär \\
\hline & bread & /bred/ & das Brot & /bro:t/ & - & house & das Hause \\
\hline & chair & $/ \mathrm{t} \int \mathrm{e} \mathrm{a}^{2} /$ & der Stuhl & /stu:1/ & - & tractor & der Trecker \\
\hline & jacket & 'dzækit/ & die Jacke & /jaka/ & - & & die Katze \\
\hline & juice & /dzus/ & der Saft & /zaft/ & - & balloon & der Ballon \\
\hline
\end{tabular}

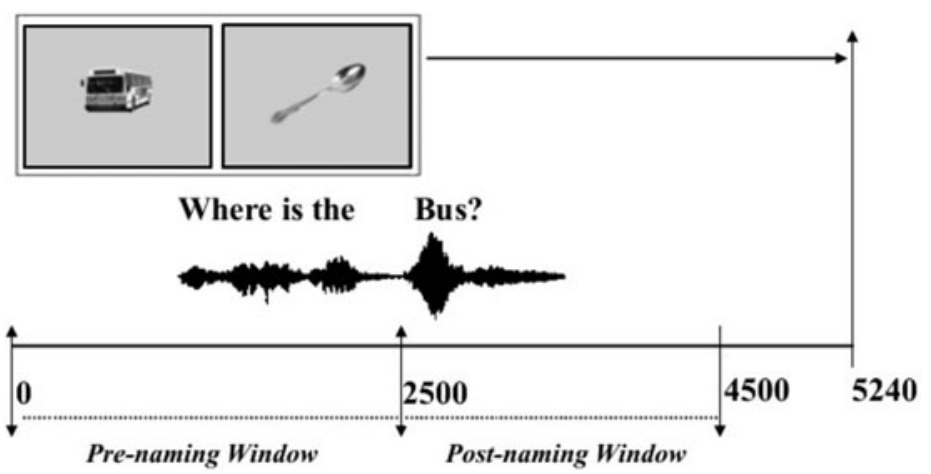

Figure 1. Schematic of the trial structure with stimulus examples. In the actual experiment, images were colorized.

\section{Procedure}

Bilingual toddlers were tested in their preschool using a standard intermodal preferential looking word recognition task and were addressed in English by the experimenter. Each toddler was tested individually in a room separated from the rest of the preschool and were tested on the
English and German versions of the experiment on separate days. Toddlers either sat alone or on the lap of a teacher. A large computer monitor placed $60 \mathrm{~cm}$ away from the participant displayed the target-distracter images. Target-distracter images measured $17.5 \times 13 \mathrm{~cm}$ and appeared side by side on the screen. Two loudspeakers presented the auditory stimuli, one on either side of the 
computer monitor. A video camera centered above the computer monitor recorded digital video images of the child during the experiment.

Monolingual toddlers were tested in a laboratory setting using the same intermodal preferential looking word recognition task and were addressed in German by the experimenter. Each toddler either sat alone or sat on the lap of a parent $60 \mathrm{~cm}$ away from a large television screen. Target-distracter images measured $27 \times 20 \mathrm{~cm}$ and appeared side by side on the screen. Two loudspeakers situated above the televisions screen presented the auditory stimuli. Two video cameras centered above the television screen recorded digital images of the child during the experiment.

Although the experimental conditions were kept as similar as possible for monolingual and bilingual toddlers, there were some differences. Due to the requirements of the preschool, the experimenter was required to speak English with the bilingual toddlers. With the monolingual toddlers in Experiment 1, however, the experimenter spoke German, as this was the only language the monolingual toddlers understood. In addition, the bilingual toddlers were tested in a preschool setting and never accompanied by a parent, whereas the monolingual toddlers were tested in a laboratory setting and always accompanied by a parent.

\section{Analysis}

The video images were coded offline using the Look software (Meints \& Woodford, 2008), by a coder, blind to the images, auditory stimuli, and condition, to determine the direction of children's fixations during the experiment (every $40 \mathrm{~ms}$ ). A second skilled coder coded $10 \%$ of the participant data, verifying a high percentage of coder agreement, $r(14)=.988, p<.0001$. The coded video images provided a measure of the amount of time toddlers spent looking at target (T) and distracter (D) during both the pre-naming phase - before the target was labeled and the post-naming phase - after the target was labeled. With the aid of the R package eyetrackingR (Dink \& Ferguson, 2015), we calculated the proportion of time toddlers spent looking at the target $(\mathrm{PTL}=\mathrm{T} /(\mathrm{T}+\mathrm{D}))$. Looks not directed at the target or distractor were coded as missing. As in previous work (e.g., Mani \& Plunkett, 2011b), only those trials where toddlers fixated the target and the distractor at least once during the pre-naming phase (before target word onset at $2500 \mathrm{~ms}$ ) were included in the analysis. For monolingual toddlers, this removed $25(8 \%)$ and $29(9 \%)$ trials for the English and German versions, respectively. For bilingual toddlers, this removed $32(6 \%)$ and $43(8 \%)$ trials for the English and German versions, respectively.

Target fixation proportion was logit transformed using an adjustment for data that is exactly 0 or 1 , which is undefined. Although the raw proportion of target looking is typically reported in IPL studies, confidence intervals around estimates of proportion values can fall outside of physically possible values (less than 0 , more than 1 ), whereas adjusted logit transformations (henceforth target fixations or looks) take this into consideration (for further explanation, see the Windows Analysis Vignette in the eyetrackingR package; Dink \& Ferguson, 2015). For ease of interpretation, looking estimates above 0 indicate looks to the target, while looks below 0 indicate looks to the distractor.

We used the eyetrackingR package (Dink \& Ferguson, 2015) to examine toddlers' looks to the target across the whole time course. For each toddler, the average proportion of target looks for each Word type (identical, 1-feature, 2-feature, 3-feature, and no overlap) was calculated for bins of $100 \mathrm{~ms}$. This resulted in 20 time bins. We first used non-parametric permutation analysis to examine if there is a preference for the target before it has been named (pre-naming phase), which may influence target looks in the post-naming phase, as well as to determine whether target looks were significantly greater than chance after naming (post-naming phase), indicating recognition. The permutation analysis can be used to identify clusters of time points where two conditions differ from one another or a chance value while accounting for multiple comparisons (Delle Luche, Durrant, Poltrock \& Floccia, 2015; Von Holzen \& Mani, 2012; see also Maris \& Oostenveld, 2007). For each language background (bilingual or monolingual) and each language version (German or English), we compared the full time course of target looks for each Word type (identical, 1-feature, 2 -feature, 3-feature, and no overlap) to chance $(=0)$, to determine the period of time where target looks differed significantly from chance. For each time point a t-statistic is calculated between the condition of interest and the chance value, identifying time adjacent clusters of significant t-tests $(\alpha=0.0025$, Bonferroni corrected for 20 statistical tests). The data set is then randomized 1000 times and the sums of significant clusters of tstatistics are computed at each randomization. Significant clusters from the actual and randomized data are used to compute a Monte Carlo $p$-value for each time window where a difference is identified. In the current study, we use the non-parametric permutation analysis to determine whether toddlers recognized the tested Word type.

We then examined toddlers' target looks in the postnaming phase (after target word onset at $2500 \mathrm{~ms}$ ) using growth curve analysis (GCA). Mirman and colleagues (Mirman, 2014; Mirman, Dixon \& Magnuson, 2008) describe the application of GCA to eye-tracking data analysis. It has also been applied to describe target looks in toddler word recognition (Law II \& Edwards, 2015; Von Holzen \& Mani, 2012). In contrast to mean proportions of looks to the target after naming, GCA allows us to describe 
the shape of change in target looks over time, which can more finely reflect the cognitive processes involved in word recognition. We examined target looks from the onset of the target word ( $2500 \mathrm{~ms}$ into the trial) to an end point of $2000 \mathrm{~ms}$ after target word onset $(4500 \mathrm{~ms}$ into the trial). Although previous studies have used a $1500 \mathrm{~ms}$ time window (Law II \& Edwards, 2015; Marchman \& Fernald, 2008), we used a longer $2000 \mathrm{~ms}$ time window to ensure we captured variation introduced by non-native language processing (i.e., English) and the large age range tested.

We use GCA to capture the change in target looks over time as a function of a set of predictors. To create the growth curve model, the changes in target looks over time were submitted to a mixed effects model. As in Law II and Edwards (2015) and Mirman et al. (2008) we used first and second order orthogonal polynomials (linear, quadratic) to estimate the rate (linear) and acceleration (quadratic) of looks to the target. The cubic term (third order orthogonal polynomial) was deemed unnecessary, as the response curves had no more than one bend (similar across participants and conditions). Fixed effects included Word type (identical, 1-feature, 2-feature, 3feature, and no overlap) and Age (days) at test. We computed three models. In the first model, the English Model, we compared monolingual and bilingual toddlers in their recognition of English, including Background (Back: monolingual vs. bilingual) as a fixed effect. In the second model, the German Model, we examined recognition of German, with language Background as a fixed effect. In the final model, the Bilingual Model, we compared differences in responses for the German and English versions of the test in bilingual toddlers, including Language Version (Lang_Vers: German vs. English) as a fixed effect. For the Bilingual Model, we use age of first exposure to L2 (AoA) instead of Age (see below for model comparison). All fixed effects were dummy coded and continuous predictors were centered on their mean. Across all models, responses to identical Words were coded as a reference condition, and, when included, "monolingual" and "German" were coded as the reference conditions. Participant and participant-by-condition random effects were included on all polynomial time terms.

\section{Results}

Figure 2 shows the looks to the target object for each language Background and Language Version, separated by Word type. Significant time windows are indicated by shaded rectangles and summarized in Table 2 as well as discussed in the following sections.

\section{English Version: Monolingual vs. Bilingual toddlers}

The non-parametric permutation analysis revealed recognition for the English version of all Word types for bilingual toddlers but only identical words for monolingual toddlers (Table 2). In the pre-naming window, target looks did not differ from chance, indicating no preference for target or distractor images before the target was labeled.

The output for the English Model comparing monolingual and bilingual toddlers (Background) in the English version of the experiment is shown in Table 3. Figure 3 depicts model fits for the effects of Word type, Background, and Word type by Background; and Figure 4 depicts model fits for the interaction between these effects and Age.

The results of the English Model show that in comparison to identical words, mean looks to the target were significantly lower for 2 -feature and 3-feature change words, as well as no overlap words. The main effect of Age indicates that as age increased, so did mean target looks. The 2-way interaction between the linear time term and 3-feature changes shows that over the trial, looks to the target increased at a slower rate for 3feature change words compared to identical words. The 2way interaction between 1-feature change words and Age shows that as toddler age increased, their mean target looks to 1-feature change words decreased relative to identical words. The 2-way interaction between Background and Age shows that as toddler age increased, mean target looks increased in bilingual toddlers and decreased in monolingual toddlers. The 3-way interactions between the linear time term, Background, and 3-feature change words show that over the trial, bilingual toddlers increase the rate of target looks for 3-feature change words, while monolingual toddlers decrease. The 3-way interaction between the quadratic time term, Background, and no overlap words reveals a steeper, more convex rise and fall in target looks over the time course for no overlap words in bilingual compared to monolingual toddlers.

In summary, these results show that although bilingual toddlers recognized all words, this recognition was diminished for 3-feature and no overlap words in comparison to identical words. For monolingual toddlers, this pattern was similar, although the difference was larger. Although increasing age led to increased mean looks to the target, this pattern was driven by the responses of bilingual toddlers.

\section{German Version: Monolingual vs. Bilingual toddlers}

The non-parametric permutation analysis revealed recognition for the German version of all Word types for both bilingual and monolingual toddlers (Table 2). In the pre-naming window, target looks did not differ from chance, indicating no preference for target or distractor images before the target was labeled. One exception was a single, $200 \mathrm{~ms}$ time bin for 2-feature change words in 


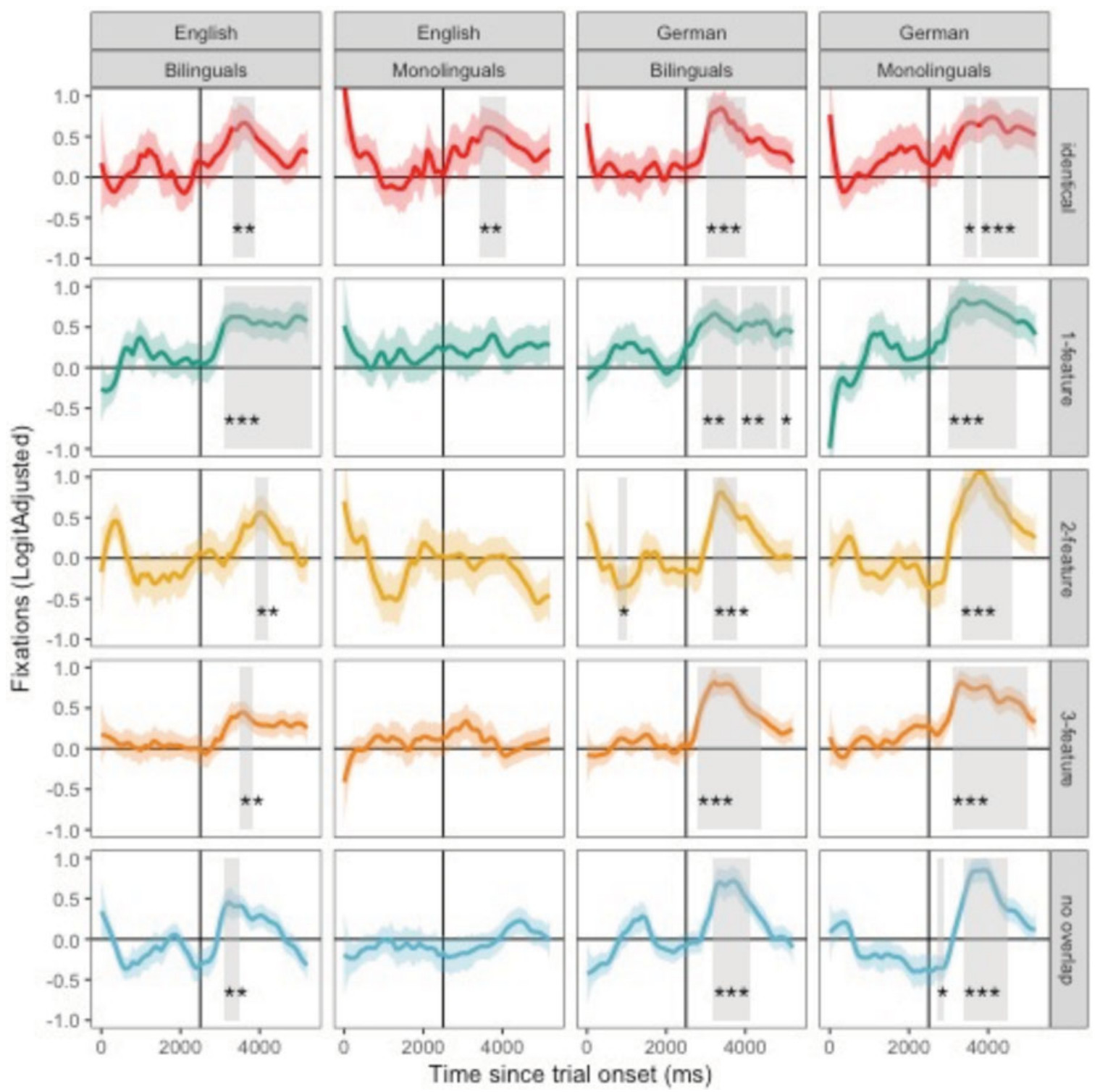

Figure 2. Fixations to the target object for each language Background and Version, separated by Word type. Time windows where fixations significantly differed from chance (Fixation Proportion $=0$ ), as identified by the non-parametric permutation analysis, are indicated by shaded rectangles $\left(p<.0001:^{* * *} ; p<.001\right.$ : $^{* *} ; p<.01:^{*} ; p<.05:$. $)$.

bilingual toddlers. Considering the short time period, as well as the return of target looks to chance before labeling occurred, we do not deem this effect to have had an impact on post-naming word recognition. In the recognition of no overlap words, monolingual toddlers show an initial preference for the distractor at the beginning of the post-naming phase (2700-2900 ms after trial onset; 200-400 ms after target word onset). Despite this initial preference, looks to the target quickly increase in the postnaming phase.

The output for the German Model comparing monolingual and bilingual toddlers (Background) in the German version of the experiment is shown in Table 4.
Figure 5 depicts model fits for the effects of Word type, Background, and Word type by Background; and Figure 6 depicts model fits for the interaction between these effects and Age.

The results of the German Model show that, in comparison to identical words, mean looks to the target were significantly lower for no overlap words. The 2way interaction between the linear time term and both 2-feature change and no overlap words shows that, for these words, looks to the target increase significantly over the time course in comparison to identical words. The 2-way interaction between the quadratic time term and 2feature change words reveals a steeper, more convex rise 
Table 2. Summary of the non-parametric permutations analysis.

\begin{tabular}{|c|c|c|c|c|c|}
\hline Language Version & Background & Word Type & Time (ms) & Summed t-statistic & Monte Carlo $p$-value \\
\hline \multirow[t]{10}{*}{ English } & \multirow[t]{5}{*}{ Bilingual } & identical & $3300-3900$ & 29.23 & $p=.001$ \\
\hline & & 1-feature & $3100-5300$ & 103.47 & $p<.0001$ \\
\hline & & 2-feature & $3900-4200$ & 12.79 & $p=.006$ \\
\hline & & 3-feature & $3500-3800$ & 10.75 & $p=.006$ \\
\hline & & no overlap & $3100-3500$ & 15.97 & $p=.003$ \\
\hline & \multirow[t]{5}{*}{ Monolingual } & identical & $3400-4100$ & 29.69 & $p=.002$ \\
\hline & & 1-feature & $\longrightarrow$ & - & - \\
\hline & & 2-feature & $\longrightarrow$ & - & - \\
\hline & & 3-feature & - & - & - \\
\hline & & no overlap & $\longrightarrow$ & - & - \\
\hline \multirow[t]{15}{*}{ German } & \multirow[t]{8}{*}{ Bilingual } & identical & $3000-4000$ & 53.94 & $p<.0001$ \\
\hline & & 1-feature & $2900-3800$ & 41.82 & $p=.001$ \\
\hline & & 1-feature & $3900-4800$ & 39.85 & $p=.001$ \\
\hline & & 1-feature & $4900-5100$ & 7.26 & $p=.034$ \\
\hline & & 2-feature & $800-1000$ & -6.95 & $p=.037$ \\
\hline & & 2-feature & $3200-3800$ & 36.71 & $p<.0001$ \\
\hline & & 3-feature & $2800-4400$ & 11.72 & $p<.0001$ \\
\hline & & no overlap & $3200-4100$ & 53.11 & $p<.0001$ \\
\hline & \multirow[t]{7}{*}{ Monolingual } & identical & $3400-3700$ & 11.29 & $p=.025$ \\
\hline & & identical & $3800-5300$ & 69.64 & $p<.0001$ \\
\hline & & 1-feature & $3000-4700$ & 95.67 & $p<.0001$ \\
\hline & & 2-feature & $3300-4600$ & 139.76 & $p<.0001$ \\
\hline & & 3-feature & $3100-5000$ & 129.03 & $p<.0001$ \\
\hline & & no overlap & $2700-2900$ & -7.05 & $p=.025$ \\
\hline & & no overlap & $3400-4500$ & 65.77 & $p<.0001$ \\
\hline
\end{tabular}

and fall in target looks over the time course to these words in comparison to identical words. The 3-way interaction between the linear time term, Age, and 1-feature change words shows that over the time course, older toddlers show an increase in looks to the target for 1-feature change words, while target looks decrease for younger toddlers.

In summary, these results reveal that word recognition in German was similar for bilingual and monolingual toddlers. Differences between word types, specifically for 2-feature and no overlap words, are arguably driven by target looks that were below chance at the onset of the target word. The interaction with the linear time term, however, indicates that target looks for these words quickly increased. Furthermore, increasing age led to increased looks to the target for 1-feature change words.

\section{Bilingual toddlers: English vs. German version}

The output for the Bilingual Model comparing bilingual toddlers in the German and English Versions of the test is shown in Table 5. Figure 7 depicts target looks with model fits for the effects of Word type, Language Version, and Word type by Language Version. To account for the wide age range of participants and subsequent wide range of toddler Age of Acquisition (AoA), we used model comparison to determine which factor to include in our Bilingual Model. Age and AoA were highly correlated, $\mathrm{r}(31)=0.70, \mathrm{p}<.001$ and likelihood ratio test revealed that adding both Age $(\chi 2(30)=74.50, \mathrm{p}<0.001)$ and AoA $(\chi 2(30)=127.00, p<0.001)$ significantly increased the goodness of fit. The model with AoA, however, significantly improved the goodness of fit in comparison to the model with Age, $\chi 2(1)=52.48, \mathrm{p}<0.001$. Considering this difference, we therefore included AoA and not toddler Age in our Bilingual Model. Figure 8 depicts the model fits for the interaction between these effects and AoA.

The results of the Bilingual Model revealed a 2-way interaction between the linear time term and 2-feature change words, indicating that, over the time course, looks to the target increased significantly for these words in comparison to identical words. The 2-way interaction between the quadratic time term and Language Version indicates a steeper, more convex rise and fall in target 
Table 3. Output of the mixed effects English Model for target looks in the English version of the experiment. Model Construction: LogitAdjusted $\sim\left(\right.$ Linear + Quadratic) ${ }^{*}$ features $*$ Language_Background $*$ Age + $(1+$ Linear + Quadratic / subj $)+(1+$ Linear + Quadratic / subj:features $)$

\begin{tabular}{|c|c|c|c|c|c|}
\hline Fixed Effects & Estimate & SE & $\mathrm{df}$ & t value & $\operatorname{Pr}(>|t|)$ \\
\hline (Intercept) & 0.42 & 0.10 & 261.00 & 4.26 & $0.00^{* * *}$ \\
\hline Linear & 0.52 & 0.33 & 257.23 & 1.56 & 0.12 \\
\hline Quadratic & -0.40 & 0.25 & 275.37 & -1.60 & 0.11 \\
\hline features 1 & -0.16 & 0.13 & 218.38 & -1.21 & 0.23 \\
\hline features 2 & -0.42 & 0.13 & 220.24 & -3.18 & $0.00^{* *}$ \\
\hline features 3 & -0.32 & 0.13 & 203.73 & -2.47 & $0.01^{*}$ \\
\hline no_overlap & -0.49 & 0.13 & 203.55 & -3.81 & $0.00^{* * *}$ \\
\hline Lang_Back & -0.08 & 0.13 & 263.51 & -0.65 & 0.51 \\
\hline Age & -0.31 & 0.13 & 264.84 & -2.33 & $0.02^{*}$ \\
\hline Linear:features1 & -0.53 & 0.44 & 220.49 & -1.21 & 0.23 \\
\hline Linear:features2 & -0.55 & 0.44 & 224.35 & -1.25 & 0.21 \\
\hline Linear:features3 & -1.11 & 0.43 & 195.28 & -2.61 & $0.01^{* *}$ \\
\hline Linear:no_overlap & 0.09 & 0.43 & 194.89 & 0.21 & 0.84 \\
\hline Quadratic:features1 & 0.18 & 0.33 & 246.13 & 0.56 & 0.58 \\
\hline Quadratic:features2 & 0.50 & 0.33 & 258.13 & 1.51 & 0.13 \\
\hline Quadratic:features3 & 0.14 & 0.31 & 200.13 & 0.46 & 0.64 \\
\hline Quadratic:no_overlap & 0.61 & 0.31 & 199.72 & 1.95 & 0.05 \\
\hline Linear:Lang_Back & -0.32 & 0.44 & 261.73 & -0.74 & 0.46 \\
\hline Quadratic:Lang_Back & -0.10 & 0.33 & 281.79 & -0.29 & 0.77 \\
\hline features1:Lang_Back & 0.29 & 0.17 & 218.70 & 1.73 & 0.09 \\
\hline features2:Lang_Back & 0.28 & 0.17 & 222.60 & 1.63 & 0.10 \\
\hline features3:Lang_Back & 0.18 & 0.17 & 204.92 & 1.10 & 0.27 \\
\hline no_overlap:Lang_Back & 0.32 & 0.17 & 205.14 & 1.88 & 0.06 \\
\hline Linear:Age & -0.56 & 0.45 & 263.07 & -1.25 & 0.21 \\
\hline Quadratic:Age & -0.32 & 0.34 & 288.83 & -0.95 & 0.34 \\
\hline features1:Age & 0.43 & 0.18 & 218.21 & 2.44 & $0.02^{*}$ \\
\hline features2:Age & 0.29 & 0.18 & 222.08 & 1.67 & 0.10 \\
\hline features3:Age & 0.24 & 0.17 & 204.09 & 1.37 & 0.17 \\
\hline no_overlap:Age & 0.33 & 0.17 & 204.15 & 1.90 & 0.06 \\
\hline Lang_Back:Age & 0.38 & 0.15 & 263.33 & 2.52 & $0.01^{*}$ \\
\hline Linear:features1:Lang_Back & 1.02 & 0.58 & 221.59 & 1.77 & 0.08 \\
\hline Linear:features2:Lang_Back & 1.10 & 0.58 & 228.62 & 1.89 & 0.06 \\
\hline Linear:features3:Lang_Back & 1.36 & 0.56 & 197.76 & 2.43 & $0.02^{*}$ \\
\hline Linear:no_overlap:Lang_Back & 0.34 & 0.56 & 197.88 & 0.61 & 0.54 \\
\hline Quadratic:features1:Lang_Back & -0.24 & 0.43 & 247.89 & -0.57 & 0.57 \\
\hline Quadratic:features2:Lang_Back & 0.03 & 0.44 & 262.61 & 0.08 & 0.94 \\
\hline Quadratic:features3:Lang_Back & -0.08 & 0.41 & 203.67 & -0.20 & 0.84 \\
\hline Quadratic:no_overlap:Lang_Back & -0.86 & 0.41 & 203.62 & -2.10 & $0.04^{*}$ \\
\hline Linear:features1:Age & 0.67 & 0.59 & 221.64 & 1.13 & 0.26 \\
\hline Linear:features2:Age & 0.91 & 0.59 & 226.67 & 1.52 & 0.13 \\
\hline Linear:features3:Age & 0.05 & 0.57 & 196.60 & 0.09 & 0.93 \\
\hline Linear:no_overlap:Age & 0.20 & 0.57 & 196.38 & 0.35 & 0.72 \\
\hline Quadratic:features 1:Age & 0.36 & 0.44 & 251.60 & 0.81 & 0.42 \\
\hline Quadratic:features2:Age & 0.86 & 0.45 & 267.73 & 1.90 & 0.06 \\
\hline Quadratic:features3:Age & 0.30 & 0.42 & 204.50 & 0.70 & 0.48 \\
\hline
\end{tabular}


Table 3. Continued.

\begin{tabular}{lccccc}
\hline \hline Fixed Effects & Estimate & SE & df & t value & $\operatorname{Pr}(>|\mathrm{t}|)$ \\
\hline Quadratic:no_overlap:Age & 0.21 & 0.42 & 204.72 & 0.50 & 0.61 \\
Linear:Lang_Back:Age & 0.72 & 0.51 & 261.17 & 1.41 & 0.16 \\
Quadratic:Lang_Back:Age & 0.08 & 0.39 & 285.28 & 0.21 & 0.83 \\
features1:Lang_Back:Age & -0.38 & 0.20 & 217.48 & -1.89 & 0.06 \\
features2:Lang_Back:Age & -0.20 & 0.20 & 221.41 & -1.01 & 0.31 \\
features3:Lang_Back:Age & -0.17 & 0.20 & 203.88 & -0.84 & 0.40 \\
no_overlap:Lang_Back:Age & -0.32 & 0.20 & 203.88 & -1.62 & 0.11 \\
Linear:features1:Lang_Back:Age & -0.90 & 0.68 & 220.23 & -1.33 & 0.19 \\
Linear:features2:Lang_Back:Age & -1.00 & 0.68 & 225.90 & -1.48 & 0.14 \\
Linear:features3:Lang_Back:Age & -0.03 & 0.66 & 196.27 & -0.05 & 0.96 \\
Linear:no_overlap:Lang_Back:Age & -0.21 & 0.66 & 195.87 & -0.32 & 0.75 \\
Quadratic:features1:Lang_Back:Age & -0.14 & 0.51 & 248.82 & -0.27 & 0.79 \\
Quadratic:features2:Lang_Back:Age & -0.45 & 0.52 & 263.96 & -0.88 & 0.38 \\
Quadratic:features3:Lang_Back:Age & -0.41 & 0.48 & 203.44 & -0.86 & 0.39 \\
Quadratic:no_overlap:Lang_Back:Age & -0.12 & 0.48 & 203.19 & -0.24 & 0.81 \\
\hline \hline
\end{tabular}

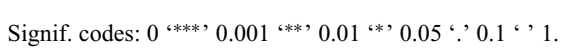

\section{a. Word type}

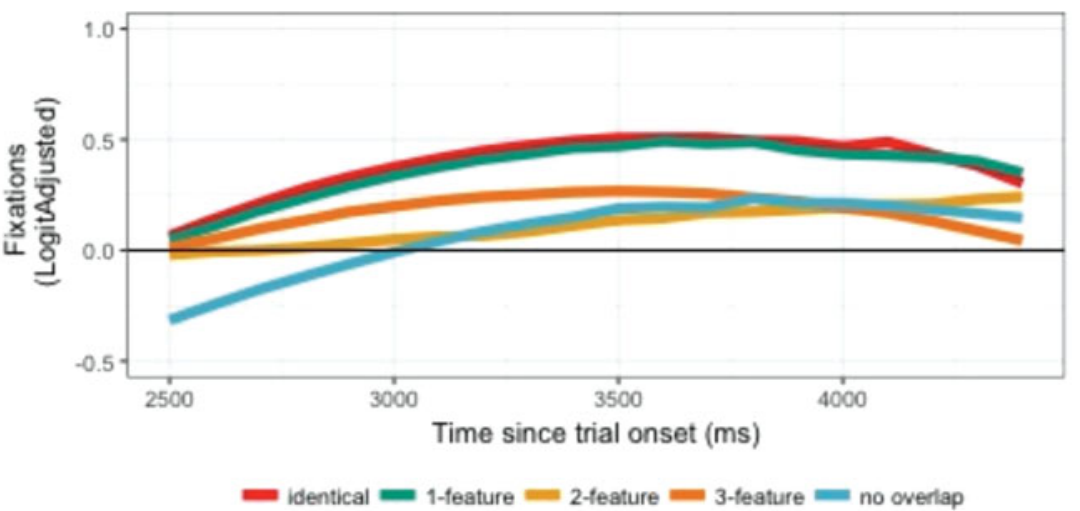

b. Background

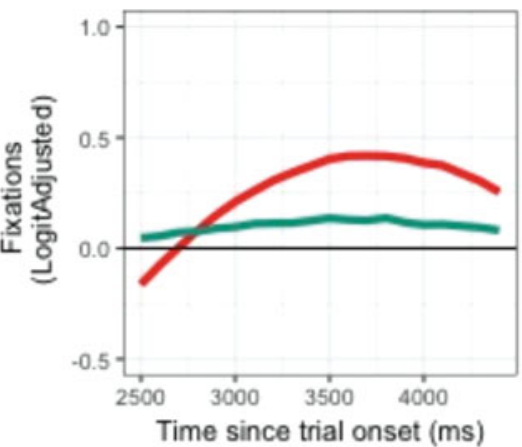

- Bilinguals - Monolinguals

c. Word type by Background

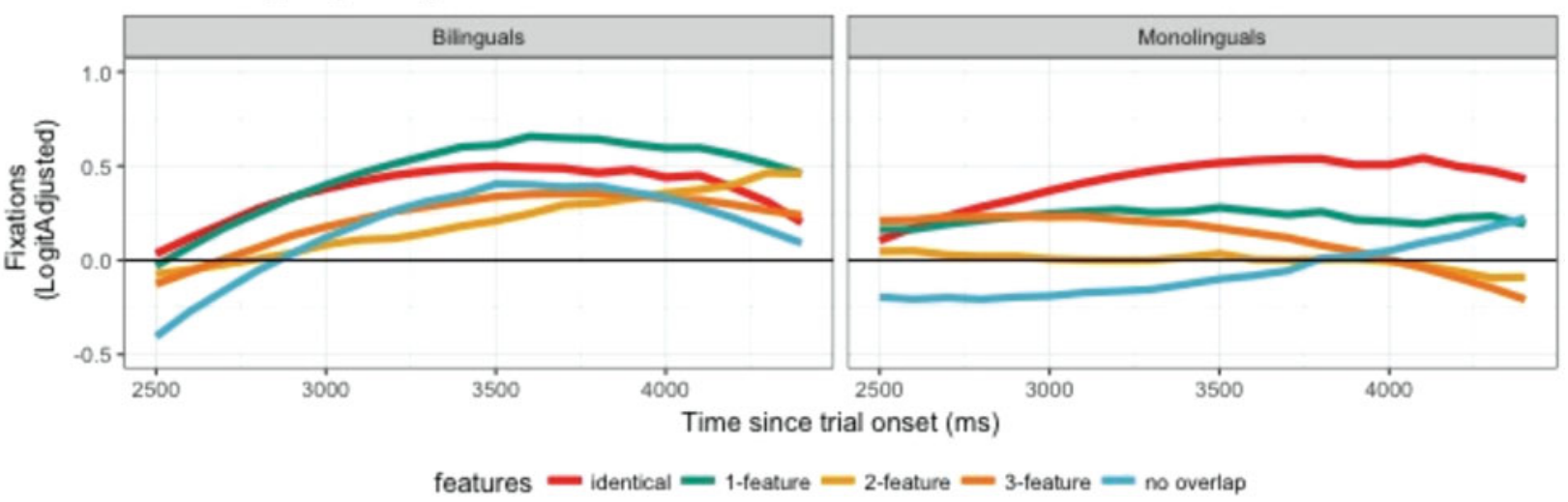

Figure 3. Model fits for the English Model, depicting fixations to the target object in the post-naming phase of the English version for the effects of a) Word type, b) Language Background, and c) Word type by Language Background. 
a. Word type by Age

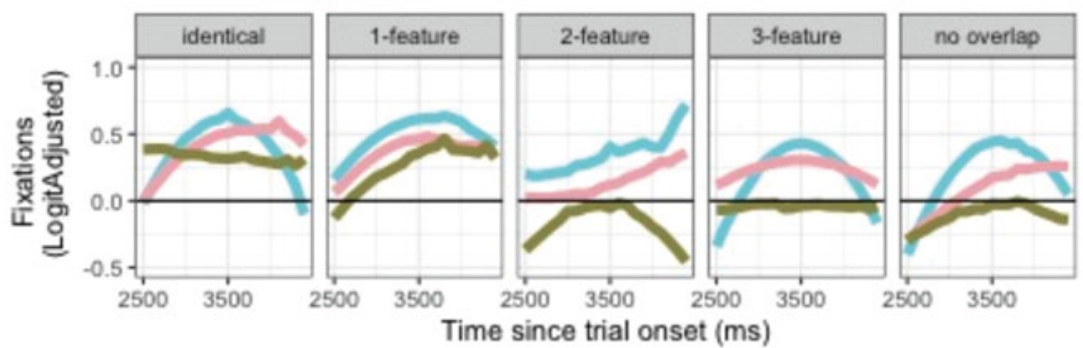

b. Background by Age



c. Word type by Background by Age
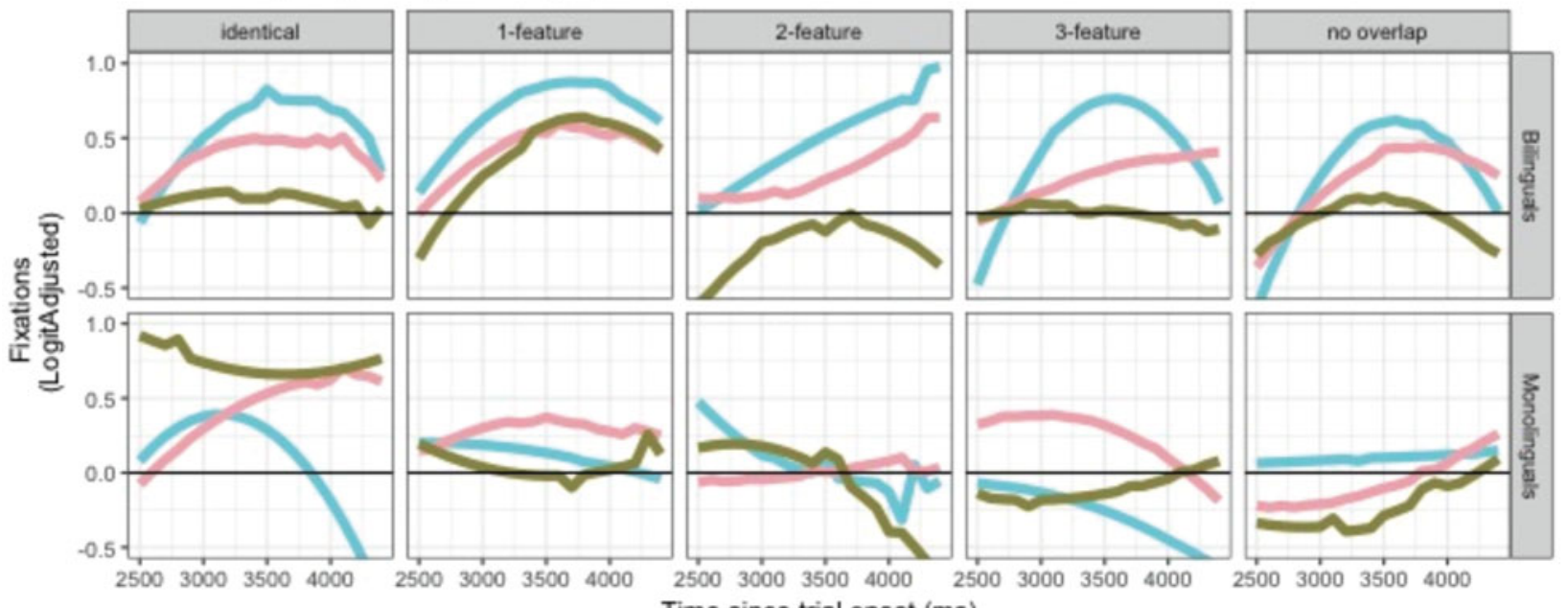

Time since trial onset (ms)

$=>$ 1SD_above $=$ Mean_age $=>$ 1SD_below

Figure 4. Model fits for the English Model including Age interactions, depicting fixations for the effects of a) Word type by Age, b) Language Background by Age, and c) Word type by Language Background by Age. For illustrative purposes, participants were grouped into whether their age was greater than 1SD below the group mean, within 1SD of the mean, or greater than $1 \mathrm{SD}$ above.

looks for the German compared to the English version of the experiment. The 2-way interaction between Language Version and both 3 -feature change and no overlap words indicates that the mean difference in target looks between these words and identical words is greater in the English version than the German version, with better recognition demonstrated for identical words. The 3-way interactions between the linear time term, Language Version, and 3feature change words shows that, in the English version, looks to the target for 3-feature change words increase at a slower rate than that of identical words. The 3-way interactions between the quadratic time term, Language Version, and 1-feature and 3-feature change words as well as no overlap words shows a steeper, more convex rise and fall in target looks for these words in the German compared to English version. The 3-way interaction between 3-feature change words, AoA and both linear and quadratic time terms show that, in comparison to identical words, looks to the target increase over the time course and are steeper with a more convex rise and fall as toddler AoA increased. The 3-way interaction between the quadratic time term, Language Version, and AoA shows that target looks had a steeper, more convex rise and fall in the English version with a greater AoA. The 4way interactions between the linear time term, Language Version, AoA, and both 2-feature and 3-feature changes words shows that, in comparison to identical words, the increase in rate of looks to the target over the time course with increasing AoA in the German version is greater for 2 -feature change words and lower for 3-feature change words. The 4-way interactions between the quadratic time term, Language Version, AoA, and both 3-feature change and no overlap words shows that in the German version, looks to the target for these words were steeper and more convex with increasing AoA.

In summary, these results reveal that overall recognition had a more typical (convex) response curve in German compared to English, although increased AoA led to more typical response in the English version. In general, bilingual toddlers with a later AoA had faster 
Table 4. Output of the mixed effects German Model for target looks in the German version of the experiment. Model Construction: LogitAdjusted $\sim($ Linear + Quadratic $) *$ features $*$ Language_Background $*$ Age + $(1+$ Linear + Quadratic / subj $)+(1+$ Linear + Quadratic / subj:features $)$

\begin{tabular}{|c|c|c|c|c|c|}
\hline Fixed Effects & Estimate & $\mathrm{SE}$ & $\mathrm{df}$ & $\mathrm{t}$ value & $\operatorname{Pr}(>|\mathrm{t}|)$ \\
\hline (Intercept) & 0.56 & 0.08 & 242.61 & 6.78 & $0.00^{* * *}$ \\
\hline Linear & 0.81 & 0.34 & 259.99 & 2.39 & $0.02^{*}$ \\
\hline Quadratic & -0.40 & 0.25 & 284.02 & -1.61 & 0.11 \\
\hline features 1 & 0.07 & 0.11 & 224.13 & 0.67 & 0.50 \\
\hline features 2 & -0.09 & 0.11 & 225.08 & -0.80 & 0.43 \\
\hline features3 & 0.02 & 0.10 & 206.32 & 0.16 & 0.88 \\
\hline no_overlap & -0.25 & 0.10 & 206.08 & -2.37 & $0.02^{*}$ \\
\hline Lang_Back & -0.13 & 0.11 & 242.60 & -1.16 & 0.25 \\
\hline Age & 0.07 & 0.11 & 234.53 & 0.66 & 0.51 \\
\hline Linear:features1 & -0.11 & 0.44 & 247.39 & -0.24 & 0.81 \\
\hline Linear:features2 & 1.18 & 0.45 & 247.99 & 2.65 & $0.01^{* *}$ \\
\hline Linear:features3 & -0.11 & 0.43 & 224.66 & -0.26 & 0.79 \\
\hline Linear:no_overlap & 0.86 & 0.43 & 224.38 & 1.99 & $0.05^{*}$ \\
\hline Quadratic:features1 & -0.25 & 0.34 & 276.76 & -0.72 & 0.48 \\
\hline Quadratic:features2 & -0.70 & 0.35 & 276.29 & -2.03 & $0.04^{*}$ \\
\hline Quadratic:features3 & -0.27 & 0.33 & 236.29 & -0.83 & 0.41 \\
\hline Quadratic:no_overlap & -0.57 & 0.33 & 235.66 & -1.73 & 0.09 \\
\hline Linear:Lang_Back & -0.47 & 0.44 & 260.97 & -1.07 & 0.28 \\
\hline Quadratic:Lang_Back & -0.33 & 0.32 & 283.49 & -1.04 & 0.30 \\
\hline features1:Lang_Back & 0.02 & 0.14 & 224.89 & 0.15 & 0.88 \\
\hline features2:Lang_Back & -0.03 & 0.14 & 226.28 & -0.24 & 0.81 \\
\hline features3:Lang_Back & 0.07 & 0.14 & 206.47 & 0.49 & 0.63 \\
\hline no_overlap:Lang_Back & 0.17 & 0.14 & 206.57 & 1.28 & 0.20 \\
\hline Linear:Age & -0.66 & 0.45 & 250.70 & -1.47 & 0.14 \\
\hline Quadratic:Age & -0.22 & 0.32 & 271.90 & -0.67 & 0.50 \\
\hline features 1:Age & -0.10 & 0.14 & 220.67 & -0.70 & 0.49 \\
\hline features 2:Age & -0.05 & 0.14 & 220.51 & -0.36 & 0.72 \\
\hline features3:Age & -0.03 & 0.14 & 201.68 & -0.22 & 0.83 \\
\hline no_overlap:Age & 0.05 & 0.14 & 202.21 & 0.38 & 0.71 \\
\hline Lang_Back:Age & -0.09 & 0.13 & 235.70 & -0.75 & 0.45 \\
\hline Linear:features1:Lang_Back & 0.04 & 0.58 & 248.53 & 0.08 & 0.94 \\
\hline Linear:features2:Lang_Back & -0.69 & 0.58 & 249.94 & -1.19 & 0.24 \\
\hline Linear:features3:Lang_Back & 0.12 & 0.56 & 225.32 & 0.22 & 0.82 \\
\hline Linear:no_overlap:Lang_Back & -0.51 & 0.56 & 225.71 & -0.90 & 0.37 \\
\hline Quadratic:features1:Lang_Back & 0.60 & 0.45 & 276.89 & 1.35 & 0.18 \\
\hline Quadratic:features2:Lang_Back & 0.44 & 0.45 & 278.65 & 0.98 & 0.33 \\
\hline Quadratic:features3:Lang_Back & 0.07 & 0.43 & 236.37 & 0.16 & 0.87 \\
\hline Quadratic:no_overlap:Lang_Back & 0.39 & 0.43 & 236.75 & 0.92 & 0.36 \\
\hline Linear:features 1:Age & 1.18 & 0.59 & 243.31 & 2.00 & $0.05^{*}$ \\
\hline Linear:features2:Age & 0.52 & 0.60 & 242.63 & 0.87 & 0.38 \\
\hline Linear:features3:Age & 0.55 & 0.58 & 218.98 & 0.96 & 0.34 \\
\hline Linear:no_overlap:Age & 0.47 & 0.58 & 219.49 & 0.82 & 0.41 \\
\hline Quadratic:features1:Age & 0.02 & 0.46 & 270.51 & 0.05 & 0.96 \\
\hline Quadratic:features2:Age & 0.01 & 0.46 & 268.60 & 0.02 & 0.98 \\
\hline Quadratic:features3:Age & -0.01 & 0.44 & 228.00 & -0.02 & 0.98 \\
\hline
\end{tabular}


Table 4. Continued.

\begin{tabular}{lccccc}
\hline \hline Fixed Effects & Estimate & SE & df & t value & $\operatorname{Pr}(>|\mathrm{t}|)$ \\
\hline Quadratic:no_overlap:Age & -0.01 & 0.44 & 228.97 & -0.03 & 0.98 \\
Linear:Lang_Back:Age & 0.63 & 0.51 & 252.86 & 1.23 & 0.22 \\
Quadratic:Lang_Back:Age & -0.01 & 0.37 & 274.65 & -0.02 & 0.99 \\
features1:Lang_Back:Age & 0.22 & 0.16 & 221.69 & 1.37 & 0.17 \\
features2:Lang_Back:Age & 0.24 & 0.16 & 221.76 & 1.49 & 0.14 \\
features3:Lang_Back:Age & 0.15 & 0.16 & 202.53 & 0.93 & 0.35 \\
no_overlap:Lang_Back:Age & 0.00 & 0.16 & 202.99 & 0.01 & 0.99 \\
Linear:features1:Lang_Back:Age & -0.88 & 0.68 & 245.29 & -1.30 & 0.19 \\
Linear:features2:Lang_Back:Age & -0.30 & 0.68 & 244.75 & -0.44 & 0.66 \\
Linear:features3:Lang_Back:Age & -0.70 & 0.66 & 220.43 & -1.07 & 0.29 \\
Linear:no_overlap:Lang_Back:Age & -0.41 & 0.66 & 220.99 & -0.62 & 0.54 \\
Quadratic:features1:Lang_Back:Age & 0.30 & 0.52 & 272.08 & 0.58 & 0.56 \\
Quadratic:features2:Lang_Back:Age & 0.34 & 0.53 & 271.65 & 0.64 & 0.52 \\
Quadratic:features3:Lang_Back:Age & 0.26 & 0.50 & 229.99 & 0.52 & 0.61 \\
Quadratic:no_overlap:Lang_Back:Age & 0.25 & 0.50 & 230.73 & 0.51 & 0.61 \\
\hline \hline
\end{tabular}

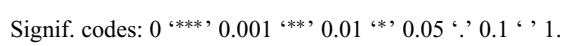

a. Word type

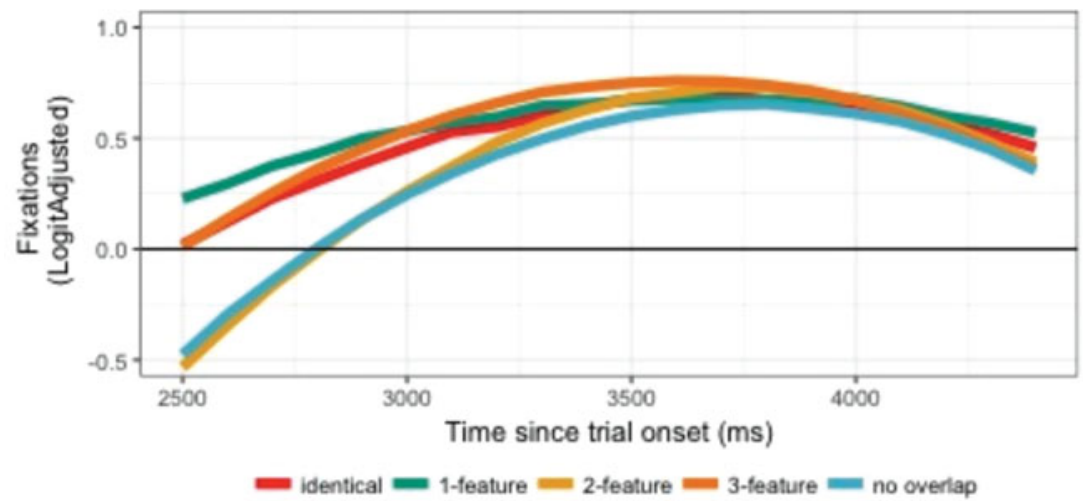

b. Background

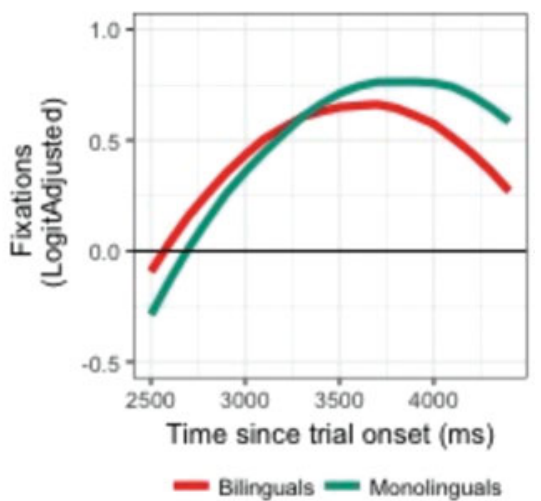

c. Word type by Background

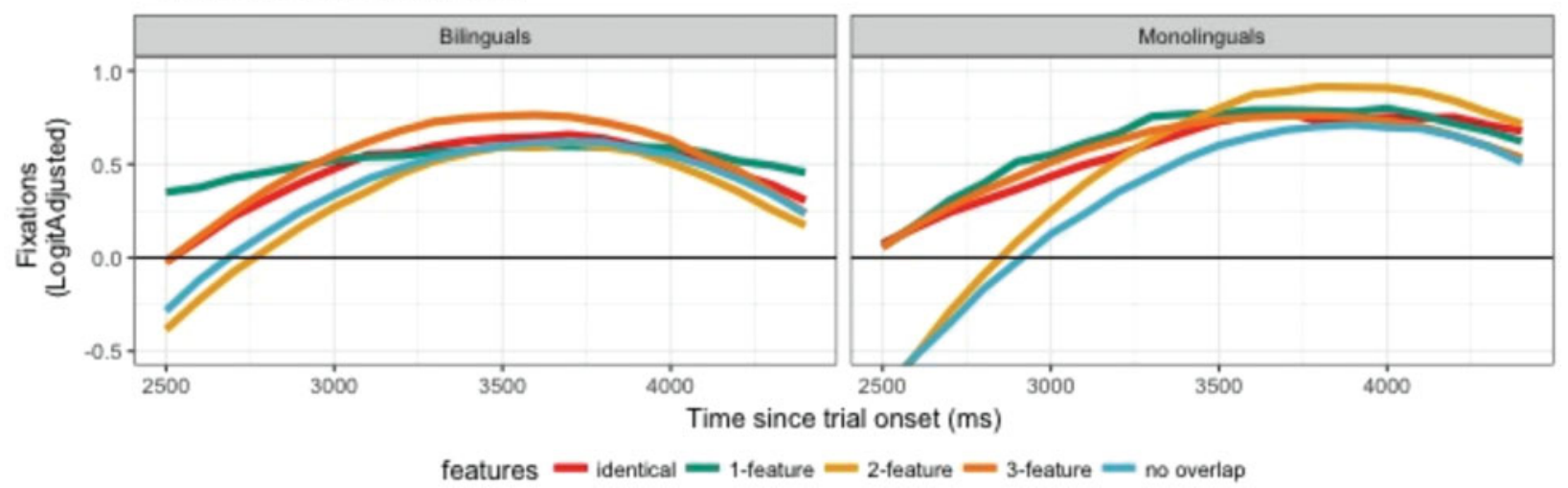

Figure 5. Model fits for the German Model, depicting fixations to the target object in the post-naming phase of the German version for the effects of a) Word type, b) Background, and c) Word type by Background. 

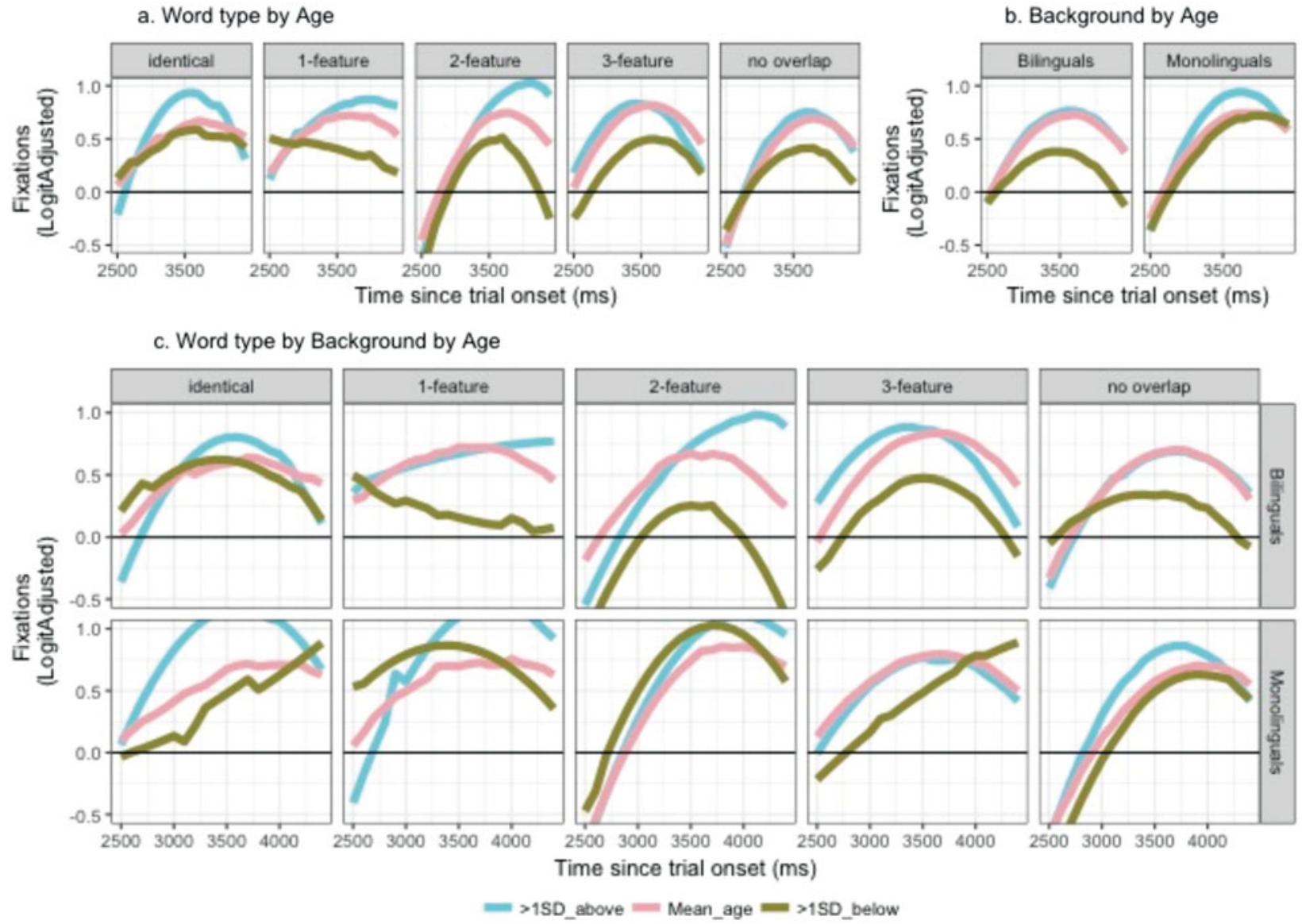

Figure 6. Model fits for the German Model including Age interactions, depicting fixations for the effects of a) Word type by Age, b) Background by Age, and c) Word type by Background by Age. For illustrative purposes, participants were grouped into whether their age was greater than 1SD below the group mean, within 1SD of the mean, or greater than 1SD above.

looks to the target for both 2-feature and 3-feature change words.

\section{Discussion}

In the current study, we examined monolingual and bilingual toddlers' recognition of words that varied in their degree of phonological overlap between German and English. The differences in recognition between monolingual and bilingual toddlers with respect to English and German words, as well as between English and German for bilingual toddlers, have implications for our understanding of patterns of bilingual phonological and lexical (word) acquisition.

When tested in English, the permutation clusters analysis revealed that bilingual toddlers demonstrated recognition of all word types tested, whereas monolingual toddlers only recognized identical words. This overall difference between the two groups in word recognition for English words reflects the obvious impact of exposure to L2 English in the bilingual preschool. Turning to the results of the GCA English Model, for both groups, overall recognition of identical words was significantly greater than that of 3-feature and no overlap words, and, for monolingual toddlers, the difference between 3 -feature change and identical words was even greater than that of bilinguals. The GCA English Model, which was used to capture differences in target looks between conditions, revealed a lack of an overall difference between identical and 1-feature changes in monolingual toddlers. Although the response for 1-feature change words was similar to identical words, it did not reach the significance threshold in the permutation clusters analysis, which would indicate recognition. This extends previous studies, which find that monolingual toddlers tolerate 1-feature mispronunciations within the native-language phonology (White \& Morgan, 2008), to recognition of words from an unknown, foreign language that are phonologically identical to or differ by 1 -feature from targets in the native language. This suggests that new English words which overlap phonologically with their German labels may be a helpful aid for monolingual German toddlers as they begin to learn a second language, just as phonologically similar words boost word segmentation and learning 
Table 5. Output of the mixed effects Bilingual Model for target looks for bilingual toddlers in both Language versions of the experiment. Model Construction: LogitAdjusted $\sim($ Linear + Quadratic) * features *

Language_Version *AoA $+(1+$ Linear + Quadratic / subj $)+(1+$ Linear + Quadratic / subj:features $)$

\begin{tabular}{|c|c|c|c|c|c|}
\hline Fixed Effects & Estimate & SE & df & $\mathrm{t}$ value & $\operatorname{Pr}(>|t|)$ \\
\hline (Intercept) & 0.44 & 0.08 & 185.00 & 5.23 & $0.00^{* * *}$ \\
\hline Linear & 0.55 & 0.35 & 198.00 & 1.60 & 0.11 \\
\hline Quadratic & -1.11 & 0.26 & 306.00 & -4.28 & $0.00^{* * *}$ \\
\hline features1 & 0.14 & 0.11 & 184.00 & 1.27 & 0.21 \\
\hline features 2 & 0.01 & 0.11 & 189.00 & 0.08 & 0.94 \\
\hline features3 & 0.18 & 0.11 & 159.00 & 1.66 & 0.10 \\
\hline no_overlap & -0.03 & 0.11 & 161.00 & -0.28 & 0.78 \\
\hline Lang_Vers & -0.05 & 0.06 & 14800.00 & -0.87 & 0.38 \\
\hline AoA & -0.01 & 0.09 & 180.00 & -0.12 & 0.91 \\
\hline Linear:features1 & -0.15 & 0.45 & 195.00 & -0.33 & 0.75 \\
\hline Linear:features2 & 0.98 & 0.45 & 205.00 & 2.16 & $0.03^{*}$ \\
\hline Linear:features3 & -0.67 & 0.43 & 166.00 & -1.55 & 0.12 \\
\hline Linear:no_overlap & 0.21 & 0.43 & 168.00 & 0.49 & 0.63 \\
\hline Quadratic:features1 & 0.51 & 0.35 & 250.00 & 1.45 & 0.15 \\
\hline Quadratic:features2 & 0.24 & 0.36 & 267.00 & 0.66 & 0.51 \\
\hline Quadratic:features3 & 0.29 & 0.33 & 191.00 & 0.89 & 0.38 \\
\hline Quadratic:no_overlap & 0.19 & 0.33 & 193.00 & 0.59 & 0.56 \\
\hline Linear:Lang_Vers & -0.21 & 0.27 & 14700.00 & -0.79 & 0.43 \\
\hline Quadratic:Lang_Vers & 0.69 & 0.26 & 14600.00 & 2.65 & $0.01^{* *}$ \\
\hline features1:Lang_Vers & -0.04 & 0.08 & 14700.00 & -0.44 & 0.66 \\
\hline features2:Lang_Vers & -0.06 & 0.08 & 14700.00 & -0.74 & 0.46 \\
\hline features3:Lang_Vers & -0.28 & 0.07 & 14700.00 & -3.89 & $0.00^{* * *}$ \\
\hline no_overlap:Lang_Vers & -0.16 & 0.07 & 14700.00 & -2.27 & $0.02^{*}$ \\
\hline Linear:AoA & 0.43 & 0.37 & 193.00 & 1.16 & 0.25 \\
\hline Quadratic:AoA & -0.54 & 0.27 & 293.00 & -1.96 & 0.05 \\
\hline features1:AoA & 0.11 & 0.12 & 180.00 & 0.90 & 0.37 \\
\hline features2:AoA & 0.23 & 0.12 & 186.00 & 1.93 & 0.05 \\
\hline features3:AoA & 0.16 & 0.11 & 156.00 & 1.44 & 0.15 \\
\hline no_overlap:AoA & 0.09 & 0.11 & 157.00 & 0.80 & 0.42 \\
\hline Lang_Vers:AoA & 0.03 & 0.06 & 14700.00 & 0.45 & 0.66 \\
\hline Linear:features1:Lang_Vers & 0.08 & 0.36 & 14700.00 & 0.23 & 0.82 \\
\hline Linear:features2:Lang_Vers & -0.72 & 0.38 & 14700.00 & -1.90 & 0.06 \\
\hline Linear:features3:Lang_Vers & 1.02 & 0.32 & 14700.00 & 3.17 & $0.00^{* *}$ \\
\hline Linear:no_overlap:Lang_Vers & 0.07 & 0.32 & 14700.00 & 0.22 & 0.82 \\
\hline Quadratic:features1:Lang_Vers & -0.75 & 0.36 & 14700.00 & -2.07 & $0.04^{*}$ \\
\hline Quadratic:features2:Lang_Vers & 0.53 & 0.37 & 14700.00 & 1.41 & 0.16 \\
\hline Quadratic:features3:Lang_Vers & -0.82 & 0.32 & 14700.00 & -2.59 & $0.01^{* *}$ \\
\hline Quadratic:no_overlap:Lang_Vers & -0.84 & 0.32 & 14700.00 & -2.67 & $0.01^{* *}$ \\
\hline Linear:features $1: A o A$ & 0.00 & 0.48 & 193.00 & 0.00 & 1.00 \\
\hline Linear:features2:AoA & 0.74 & 0.48 & 201.00 & 1.54 & 0.13 \\
\hline Linear:features3:AoA & -1.10 & 0.46 & 162.00 & -2.41 & $0.02 *$ \\
\hline Linear:no_overlap:AoA & -0.30 & 0.46 & 164.00 & -0.64 & 0.52 \\
\hline Quadratic:features1:AoA & 0.15 & 0.37 & 243.00 & 0.40 & 0.69 \\
\hline Quadratic:features2:AoA & 0.72 & 0.38 & 261.00 & 1.89 & 0.06 \\
\hline Quadratic:features3:AoA & 0.73 & 0.35 & 184.00 & 2.12 & $0.04^{*}$ \\
\hline
\end{tabular}


Table 5. Continued.

\begin{tabular}{lccccc}
\hline \hline Fixed Effects & Estimate & SE & df & t value & $\operatorname{Pr}(>|\mathrm{t}|)$ \\
\hline Quadratic:no_overlap:AoA & 0.52 & 0.35 & 187.00 & 1.49 & 0.14 \\
Linear:Lang_Vers:AoA & -0.41 & 0.28 & 14700.00 & -1.43 & 0.15 \\
Quadratic:Lang_Vers:AoA & 0.68 & 0.28 & 14500.00 & 2.43 & $0.02^{*}$ \\
features1:Lang_Vers:AoA & -0.09 & 0.09 & 14700.00 & -1.04 & 0.30 \\
features2:Lang_Vers:AoA & -0.05 & 0.09 & 14700.00 & -0.52 & 0.61 \\
features3:Lang_Vers:AoA & -0.07 & 0.08 & 14700.00 & -0.90 & 0.37 \\
no_overlap:Lang_Vers:AoA & -0.08 & 0.08 & 14700.00 & -0.99 & 0.32 \\
Linear:features1:Lang_Vers:AoA & -0.68 & 0.39 & 14700.00 & -1.75 & 0.08 \\
Linear:features2:Lang_Vers:AoA & -0.87 & 0.40 & 14700.00 & -2.15 & $0.03^{*}$ \\
Linear:features3:Lang_Vers:AoA & 1.39 & 0.34 & 14700.00 & 4.09 & $0.00^{* * *}$ \\
Linear:no_overlap:Lang_Vers:AoA & 0.15 & 0.34 & 14700.00 & 0.44 & 0.66 \\
Quadratic:features1:Lang_Vers:AoA & -0.44 & 0.39 & 14600.00 & -1.15 & 0.25 \\
Quadratic:features2:Lang_Vers:AoA & -0.42 & 0.40 & 14600.00 & -1.07 & 0.29 \\
Quadratic:features3:Lang_Vers:AoA & -1.64 & 0.34 & 14700.00 & -4.86 & $0.00^{* * *}$ \\
Quadratic:no_overlap:Lang_Vers:AoA & -1.13 & 0.34 & 14700.00 & -3.33 & $0.00^{* * *}$ \\
\hline \hline
\end{tabular}

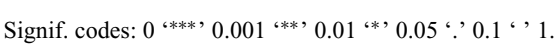

\section{a. Word type}

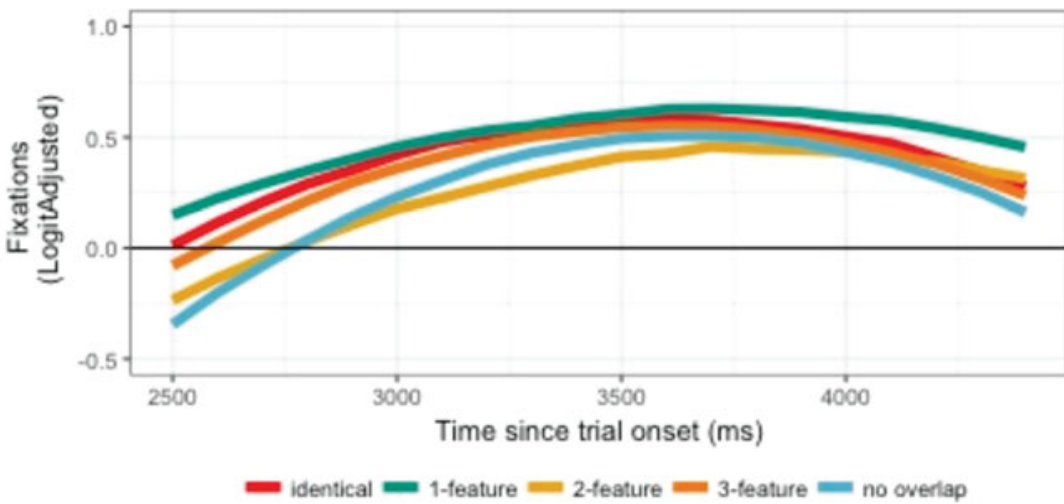

b. Language Version

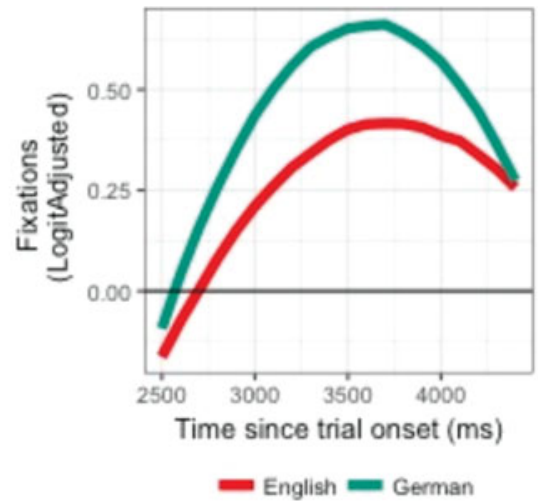

c. Word type by Language Version
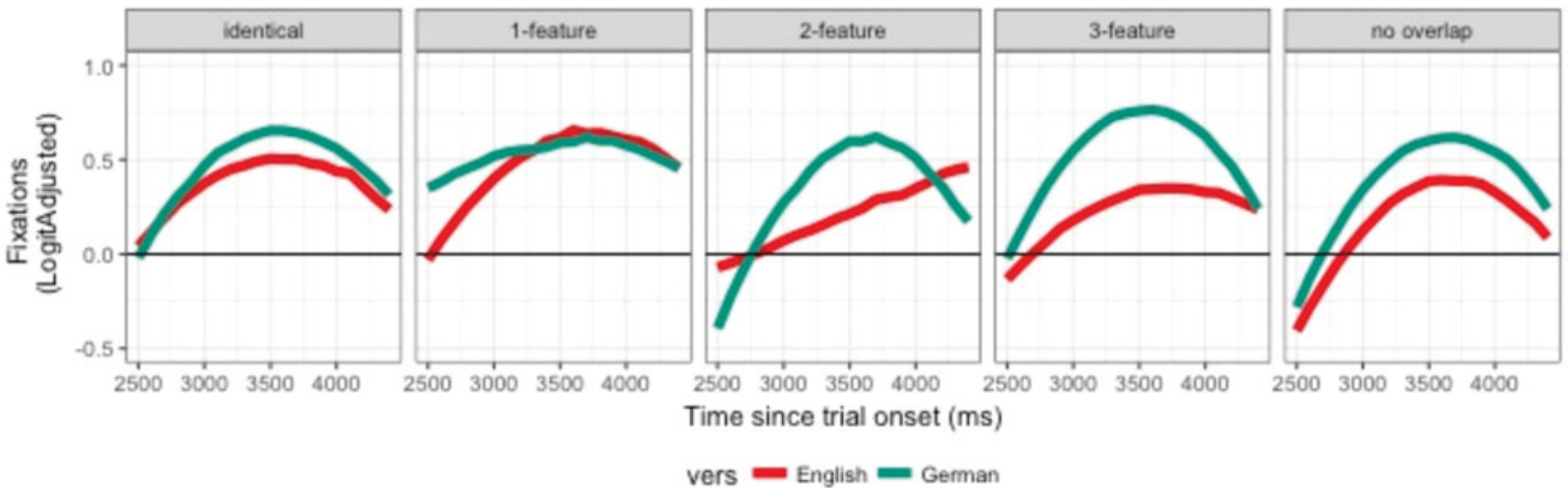

vers $=$ English $=$ German

Figure 7. Model fits for the Bilingual Model, depicting fixations to the target object in the post-naming phase for bilingual toddlers for the effects of a) Word type, b) Language Version, and c) Word type by Language Version. 
a. Word type by AoA

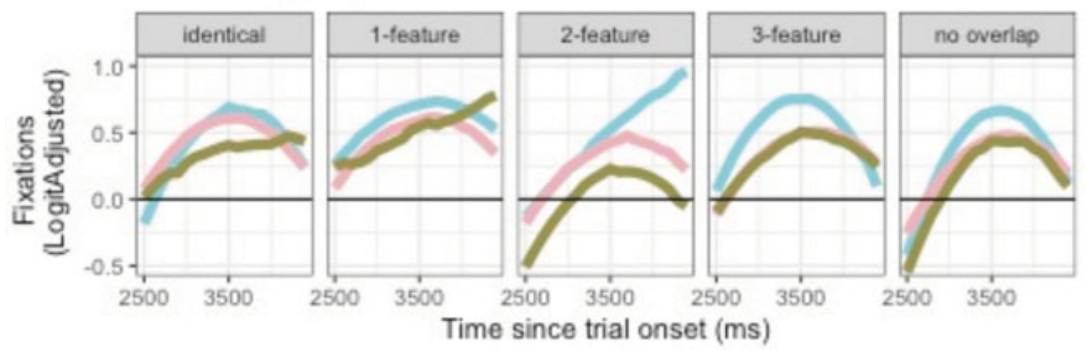

b. Language Vers. by AoA

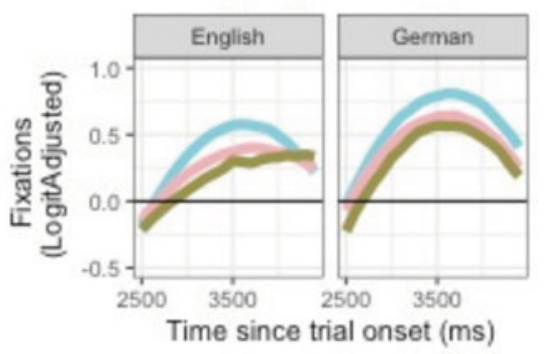

c. Word type by Language Version by AoA
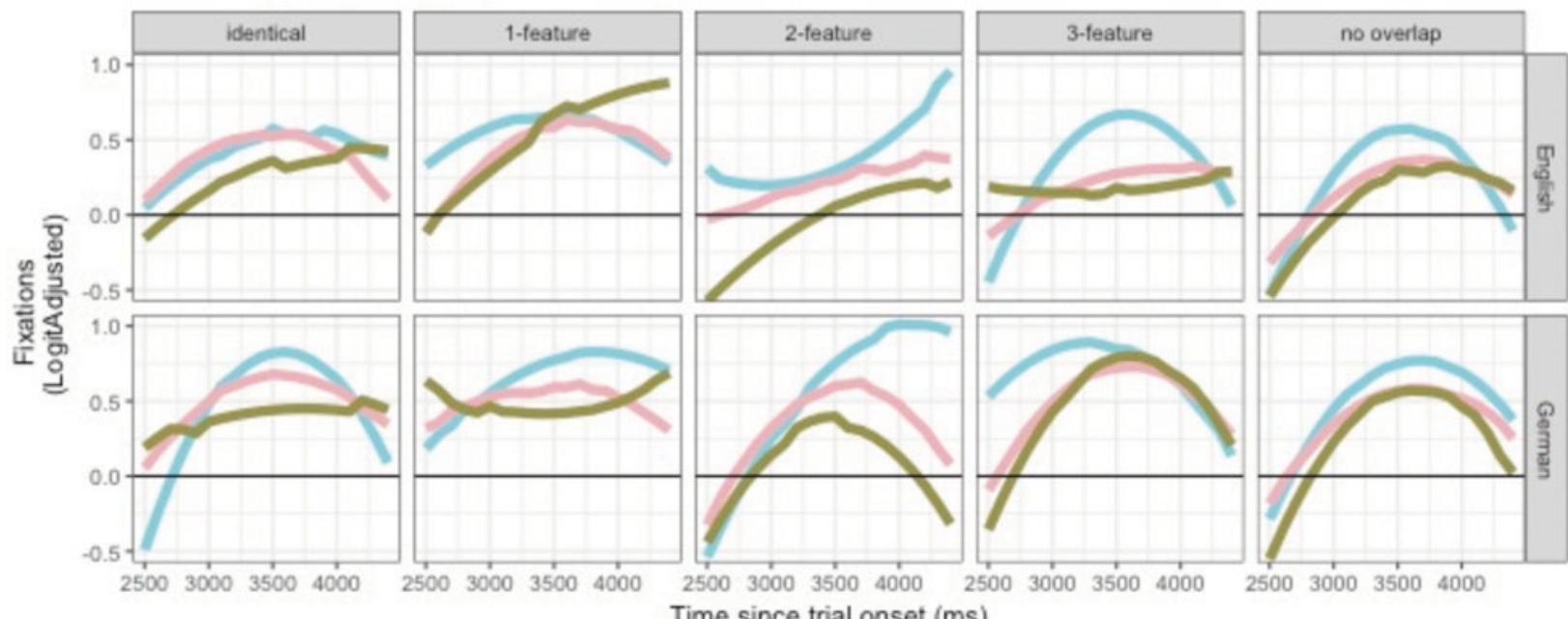

Time since trial onset (ms)

$=>$ 1SD_above $=$ Mean_AoA $=<1$ SD_below

Figure 8. Model fits for the Bilingual Model including AoA interactions, depicting fixations for the effects of a) Word type by Age of Acquisition (AoA), b) Language Version by AoA, and c) Word type by Language Version by AoA. For illustrative purposes, participants were grouped into whether their AoA was greater than 1SD below the group mean, within 1SD of the mean, or greater than $1 \mathrm{SD}$ above.

within their own first language (Altvater-Mackensen \& Mani, 2013; Newman et al., 2008). Both bilingual and monolingual toddlers exhibited recognition of identical words. Consequently, recognition of identical words tells us little about the extent to which bilingual toddlers have formed L2 specific representations of words, since monolingual toddlers with no exposure to English were also able to recognize these words.

Although bilingual toddlers recognized all words tested in English, it is important to note that their pattern of recognition was impacted by the amount of phonological overlap (i.e., number of features changed) with the German labels for words. One recent study (Wewalaarachchi et al., 2017) suggests that bilingual toddlers, like monolingual toddlers, are sensitive to 1feature mispronunciations of familiar words, whether consonant, vowel, or tone changes. Our study adds to these results by showing that when consonants and vowels are changed (between L1 and L2 word forms) but are not mispronunciations, bilingual toddlers can successfully recognize them. These findings suggest some flexibility in the extent to which bilingual toddlers access L2 specific representations and the extent to which L1 phonological knowledge impacts recognition. While recognition of 1-feature, 2-feature, 3-feature change words as well as no overlap words suggests that these toddlers were not exclusively recruiting L1 phonological knowledge during word recognition in English, the reduced recognition of these words suggests that the phonological difference between the German and English versions of the word were salient to the bilingual listener. On the one hand, this may reflect reduced experience with L2 English and therefore a reduction in word recognition, which can be bolstered by overlapping phonology between the L1 and L2. On the other hand, if both languages are simultaneously activated, this may cause increased interference between L1 and L2 representations, especially those that are phonologically similar. At this early stage of L2 exposure, it appears that young L2 learners may have difficulty in switching 
from principles of phonological distinctiveness in their $\mathrm{L} 1$, to being flexible enough with $\mathrm{L} 2$ representations, due to either reduced L2 English experience or non-selective language activation.

Despite the overlap between English and German labels, permutation analyses revealed that monolingual toddlers showed no recognition of the English counterparts that had 1-feature, 2- and 3-feature changes. The growth curve analysis, which compared conditions with one another, revealed no difference between identical and 1-feature change words. It would appear that, when confronted with a foreign language, monolingual toddlers unsurprisingly applied their L1 phonological knowledge: they correctly recognized words that were highly similar to L1 words they already knew (e.g., identical and 1feature change words), but rejected words that were not similar enough (e.g., 2- and 3-feature change words and no overlap words). This is successful behavior for toddlers who have to navigate through one language environment.

Toddler age also played a role in recognition of words in the English version of the experiment, showing that older toddlers had comparably more target looks than younger toddlers. This was driven by the response of bilingual toddlers. On the one hand, this could be due to more mature word recognition in older toddlers (Fernald, Pinto, Swingley, Weinberg \& McRoberts, 1998). As bilingual toddlers become older, their ability to recognize L2 English words increases, while increasing age unsurprisingly has no similar effect in monolingual toddlers. In contrast, this could reflect an overall impact of increased experience with English resulting in better English word recognition. Ramon-Casas and colleagues (Ramon-Casas et al., 2009) found that in simultaneous bilinguals, older toddlers are more sensitive to mispronunciations in cognate words than younger toddlers, suggesting that increased language experience is related to increased detail in the representation of familiar words. In the current study, perhaps increased age leads to increasingly more refined phonological representations of words in bilingual toddlers.

L1 German recognition in bilingual and monolingual toddlers was not modulated by similarity to English labels. For monolingual toddlers, the explanation is clear: phonological overlap between languages holds no special lexical status. For bilingual toddlers, however, phonological overlap between languages may have influenced word recognition. This suggests that similarity to L2 English labels neither aided nor hindered L1 recognition. Although preschool age toddlers are arguably far from being masters of their L1, the introduction of a second language at this early age did not have an influence on L1 word recognition.

Finally, in the Bilingual Model we compared recognition for German and English words within the bilingual toddlers. Overall, recognition was better for
German compared to English words. This is rather unsurprising, considering that all toddlers had been exposed to German since birth, while exposure to English came around their first birthday or later. For 2- and 3 -feature change and no overlap words, recognition in English, but not German, was significantly diminished compared to identical words. This set of results reflects the facilitation role that phonological overlap may play in L2 word recognition. This pattern further reflects the importance of the role of phonological overlap between languages in the recognition of L2 words. As phonological overlap in words between the two languages increases, so does recognition improve in L2 English.

For the bilingual toddlers, the age of L2 English acquisition (AoA) also influenced responses in word recognition. In general, early AoA is associated with ultimately greater L2 attainment in comparison with those who learn their L2 at a later age (for a review, see Hernandez \& Li, 2007). Children with an AoA before age 3 have improved reading skills, phonological awareness, and language competence (Kovelman, Baker \& Petitto, 2008) in comparison to their peers with an AoA between ages 3 and 6, although AoA has less influence compared to current use on children's semantic and morphosyntactic development (Bedore, Peña, Summers, Boerger, Resendiz, Greene, Bohman \& Gillam, 2012). In our study, word recognition for English words was improved for bilingual toddlers with LATER L2 English AoAs, which at first appears contrary to the current body of literature. However, we would like to stress that toddlers tested in the current study were much younger (mean 3;4-years-old, oldest 4;4-years-old) than previous studies investigating AoA effects (5-years-old, Bedore et al., 2012; 7-9-years-old, Kovelman et al., 2008). Furthermore, all of the bilingual toddlers in the current study were exposed to L2 English before the age of 3, which is typically used to define an "early AoA". Therefore, our results somewhat uniquely allow for an examination of variations of AoA within the traditionally defined early acquisition period for sequential bilinguals. Our results show that being exposed to L2 English later in toddlerhood boosted English word recognition in bilingual toddlers, particularly in the case for both 2-feature and 3-feature change words. Toddlers with a later AoA are presumably more mature in their understanding of phonology when they begin to learn an L2, which should lead to an improved ability to cope with the conflicting phonological codes between English and German. Further, considering that AoA and toddler Age were correlated (but AoA significantly improved the model fit when compared to Age), those toddlers who had later AoAs were also older and therefore may have had faster word recognition skills (Fernald et al., 1998). Future research is needed to understand how toddlers' linguistic developmental level at first exposure to an L2 impacts early word recognition. 
Facilitated recognition of words with more phonological overlap between languages (cognate words) compared to words with no overlap between languages (non-cognate words) has been found in bilingual adults for visual (Dijkstra et al., 1999, 2010; Schwartz et al., 2007) and auditory word recognition (Blumenfeld \& Marian, 2007; Schelletter, 2002). In the current study, we found that phonological similarity modulated word recognition for L2, but not L1 words. At this level of L2 acquisition it appears that, when the phonological differences between labels are large enough (i.e., 3-feature changes), this may interfere with word recognition in L2, although not L1. This may be the result of asymmetry in the bilingual toddlers' L1 and L2 proficiency. Unbalanced bilingual adults typically also show a cognate facilitation effect that is greater for L2 compared to L1 (Costa, Caramazza \& Sebastian-Gallés, 2000; Kroll \& Stewart, 1994). In this scenario, L1 words are not facilitated because the representations for their L2 equivalents are not robustly established and therefore exert no influence. For the bilingual toddlers tested in the current study, their L2 representations may also be not well established enough to facilitate recognition of phonologically overlapping words in L1.

The reduced recognition of English 2-feature and 3feature change words may be evidence of interference between representations from both languages, possibly due to simultaneous activation of both languages (Dijkstra, 2005). Some studies examining bilingual adults have also found an interference effect for cognate words (Dijkstra et al., 1999, 2010; Schwartz et al., 2007). In the current study, that 2-feature and 3-feature change words are highly similar, but not identical across languages, may underlie this potential interference effect. This highlights the role of phonology in cross-linguistic word recognition studies, showing that fairly small changes in phonological overlap between languages can impact word recognition, a point that is not typically considered in adult studies of bilingualism (see Dijkstra et al., 1999). Along similar lines, Ramon-Casas, Bosch, and colleagues $(2009 ; 2010)$ suggest that the lack of sensitivity to vowel mispronunciations in cognate words is the result of an interference effect between the similar cognate words in the bilingual toddler's two languages. As toddlers age, however, this interference effect diminishes.

\section{Limitations}

Our study has several potential limitations. As stated in the Methods section, our set of stimuli contained both vowel and consonant changes. This was deemed necessary due to the limited number of available English-German word pairs with overlapping phonology that toddlers could be expected to know at the ages tested. Previous studies with monolingual toddlers have examined consonant and vowel mispronunciations together, without separating the two (Swingley \& Aslin, 2000, 2002) as well as consonant and vowel mispronunciations separately, finding overall no difference in sensitivity to the two in monolingual (Mani \& Plunkett, 2007, 2010; Swingley, 2016) and bilingual toddlers' (Wewalaarachchi et al., 2017) word recognition. Yet, there is evidence for an asymmetry in sensitivity to consonants and vowels in infants and toddlers (Nazzi, Poltrock \& Von Holzen, 2016). Although the words tested in the current study were not mispronunciations, but actual words, further investigation would be needed to determine whether bilingual toddlers also exhibit consonant/vowel asymmetry.

Furthermore, testing in a bilingual preschool reduced our ability to control the experimental conditions. The language spoken by the experimenter at test was German for monolingual toddlers and English for bilingual toddlers (at the request of the preschool). Although language context has been found to impact L1 and L2 linguistic processing in bilingual adults (Misra, Guo, Bobb \& Kroll, 2012; Von Holzen \& Mani, 2014; Weber $\&$ Cutler, 2006), we are unaware of any study that has systematically investigated language context in bilingual toddler linguistic processing. In the current study, it is probable that the local context of English being spoken during the experiment to bilingual toddlers served to boost their word recognition in English and possibly hinder word recognition in German. However, considering that overall word recognition was better in German compared to English for bilingual toddlers, we believe that the use of English with that group does not change our conclusions.

In the bilingual preschool, bilingual toddlers were exposed to a variety of native and non-native English from non-parental sources. The English stimuli used in the current study were produced by a native speaker of American English, which did not reflect the entirety of English pronunciations that the bilingual toddlers received in their daily life. However, considering the variety of accented English the children heard, we believe our choice of stimuli was valid (i.e., one of the varieties the children heard). Non-native or non-parental input of an L2 may lead to a weaker lexical-semantic connections and therefore slower word recognition speed (DeAnda et al., 2017). In the current study, therefore, the presence of non-native English in the input of the bilingual toddlers may have resulted in diminished word recognition. Despite this eventuality, bilingual toddlers did show recognition of all English words tested, as revealed by the non-parametric permutation analysis. Future studies should examine how bilingual toddlers adapt to unfamiliar accents (e.g., Mulak et al., 2013).

Finally, we were unable to measure vocabulary in the bilingual toddler population. The parents of these toddlers did not speak English with their children. Bilingual toddlers' English vocabulary knowledge could 
only be rated by their English teachers, who were caring for many children simultaneously and therefore rendering individual vocabulary evaluations difficult. Nonetheless, recent studies suggest that vocabulary size in bilingual toddlers has an impact on their word recognition processing speed (DeAnda et al., 2017; Hurtado, Grüter, Marchman \& Fernald, 2014; Legacy, Zesiger, Friend \& Poulin-Dubois, 2016; Marchman, Fernald \& Hurtado, 2009). Although the purpose of the current study was to evaluate the impact phonological overlap of L1 and L2 word forms has on bilingual toddler word recognition, we can assume that bilingual toddlers with a bigger vocabulary are better able to appropriately apply their L1 and L2 phonological knowledge, which would lead to facilitated word learning and therefore also impact word recognition. Future studies should examine the nature of this connection.

\section{References}

Altvater-Mackensen, N., \& Mani, N. (2013). Wordform familiarity bootstraps infant speech segmentation. Developmental Science, 16(6), 980-990. http://doi.org/10.1111/desc. 12071

Arias-Trejo, N., \& Plunkett, K. (2009). Lexical-semantic priming effects during infancy. Philosophical Transactions of the Royal Society of London, 364, 3633-3647. http://doi.org/10.1098/rstb.2009.0146

Bain, B., \& Yu, A. (1980). Cognitive consequences of raising children bilingually: "One parent, one language." Canadian Journal of Psychology Revue, 34(4), 304-313.

Ballem, K. D., \& Plunkett, K. (2005). Phonological specificity in children at 1;2. Journal of Child Language, 32(1), 159-173. http://doi.org/10.1017/S0305000904006567

Bedore, L. M., Peña, E. D., Summers, C. L., Boerger, K. M., Resendiz, M. D., Greene, K., Bohman, T., \& Gillam, R. B. (2012). The measure matters: Language dominance profiles across measures in Spanish-English bilingual children. Bilingualism: Language and Cognition, 15(3), 616-629. http://doi.org/10.1017/S1366728912000090

Best, C. T., Tyler, M., Gooding, T. N., Orlando, C. B., \& Quann, C. A. (2009). Development of phonological constancy: Toddlers' perception of native- and Jamaican-accented words. Psychological Science, 20(5). http://doi.org/10.1111/j.1467-9280.2009.02327.x.

Blumenfeld, H. K., \& Marian, V. (2007). Constraints on parallel activation in bilingual spoken language processing: Examining proficiency and lexical status using eyetracking. Language and Cognitive Processes, 22(5), 633660. http://doi.org/10.1080/01690960601000746

Bosch, L., \& Ramon-Casas, M. (2014). First translation equivalents in bilingual toddlers' expressive vocabulary Does form similarity matter? International Journal of Behavioral Development, 38(4), 317-322. http://doi.org/10.1177/0165025414532559

Brenders, P., van Hell, J. G., \& Dijkstra, T. (2011). Word recognition in child second language learners:
Evidence from cognates and false friends. Journal of Experimental Child Psychology, 109(4), 383-396. http://doi.org/10.1016/j.jecp.2011.03.012

Costa, A., Caramazza, A., \& Sebastian-Galles, N. (2000). The cognate facilitation effect: Implications for models of lexical access. Journal of Experimental Psychology: Learning, Memory, and Cognition, 26(5), 1283-1296. http://doi.org/10.1037/0278-7393.26.5.1283

DeAnda, S., Hendrickson, K., Zesiger, P., Poulin-Dubois, D., \& Friend, M. (2017). Lexical access in the second year: a study of monolingual and bilingual vocabulary development. Bilingualism: Language and Cognition, 114. http://doi.org/10.1017/S1366728917000220

Delle Luche, C., Durrant, S., Poltrock, S., \& Floccia, C. (2015). A methodological investigation of the Intermodal Preferential Looking paradigm: Methods of analyses, picture selection and data rejection criteria. Infant Behavior and Development, 40, 151-172. http://doi.org/10.1016/j.infbeh.2015.05.005

Dijkstra, T. (2005). Bilingual visual word recognition and lexical access. In J. F. Kroll \& A. M. B. de Groot (Eds.), Handbook of Bilingualism: Psycholinguistic Approaches. (pp. 179201). Oxford: Oxford University Press.

Dijkstra, T., Grainger, J., \& van Heuven, W. J. B. (1999). Recognition of cognates and interlingual homographs: The neglected role of phonology. Journal of Memory and Language, 41(4), 496-518. http://doi.org/10.1006/jmla.1999.2654

Dijkstra, T., Miwa, K., Brummelhuis, B., Sappelli, M., \& Baayen, R. H. (2010). How cross-language similarity and task demands affect cognate recognition. Journal of Memory and Language, 62(3), 284-301. http://doi.org/10.1016/j.jml.2009.12.003

Dink, J. W., \& Ferguson, B. F. (2015). eyetrackingR: An R Library for Eye-tracking Data Analysis. Retrieved from http://www.eyetrackingr.com

Fernald, A., Pinto, J. P., Swingley, D., Weinberg, A., \& McRoberts, G.W. (1998). Rapid gains in speed of verbal processing by infants in the 2nd year. Psychological Science, 9(3), 228-231. http://doi.org/10.1111/1467-9280.00044

Floccia, C. (2017). Data collected with the Oxford CDI over a course of 5 years in Plymouth Babylab, UK. With the permission of Plunkett, K. and the Oxford CDI from Hamilton, A., Plunkett, K., \& Schafer, G., (2000).

Floccia, C., Sambrook, T. D., Delle Luche, C., Kwok, R., Goslin, J., White, L., . . Plunkett, K. (2018). Vocabulary of 2-yearolds learning English and an additional language: Norms and fffects of linguistic distance. In Monographs of the Society for Research in Child Development.

Genesee, F. (2010). Dual language development in preschool children. In E. Garcia \& E. Frede (Eds.), Dual language development in bilingual children: (pp. 1-39). Teacher's College Press.

Hamilton, A., Plunkett, K., \& Schafer, G. (2000). Infant vocabulary development assessed with a British communicative development inventory. Journal of Child Language, 27(3), 689-705. http://doi.org/10.1017/S0305000900004414 
Hernandez, A. E., \& Li, P. (2007). Age of acquisition: Its neural and computational mechanisms. Psychological Bulletin, 133(4), 638-650. http://doi.org/ 10.1037/0033-2909.133.4.638

Hurtado, N., Grüter, T., Marchman, V. A., \& Fernald, A. (2014). Relative language exposure, processing efficiency and vocabulary in Spanish-English bilingual toddlers. Bilingualism: Language and Cognition, 17(1), 189-202. http://doi.org/10.1017/S136672891300014X

Kovelman, I., Baker, S. A., \& Petitto, L. A. (2008). Age of first bilingual language exposure as a new window into bilingual reading development. Bilingualism: Language and Cognition, 11(2), 203-223. http://doi.org/10.1017/S1366728908003386

Kroll, J. F., \& Stewart, E. (1994). Category interference in translation and picture naming: Evidence for asymmetric connections between bilingual memory representations. Journal of Memory \& Language, 33, 149-174.

Kroll, J. F., van Hell, J. G., Tokowicz, N., \& Green, D. W. (2010). The Revised Hierarchical Model: A critical review and assessment. Bilingualism (Cambridge, England), 13(3), 373-381. http://doi.org/10.1017/S136672891000009X

Law II, F., \& Edwards, J. R. (2015). Effects of Vocabulary Size on Online Lexical Processing by Preschoolers. Language Learning and Development, 11(4), 331-355. http://doi.org/10.1080/15475441.2014.961066

Legacy, J., Zesiger, P., Friend, M., \& Poulin-Dubois, D. (2016). Vocabulary size and speed of word recognition in very young French-English bilinguals: A longitudinal study. Bilingualism: Language and Cognition, 1-13. http://doi.org/10.1017/S1366728916000833

Mallikarjun, A., Newman, R. S., \& Novick, J. M. (2017). Exploiting the interconnected lexicon: Bootstrapping English language learning in young Spanish speakers. Translational Issues in Psychological Science, 3(1), 3447. http://doi.org/10.1037/tps0000105

Mani, N., \& Plunkett, K. (2007). Phonological specificity of vowels and consonants in early lexical representations. Journal of Memory and Language, 57(2), 252-272. http://doi.org/10.1016/j.jml.2007.03.005

Mani, N., \& Plunkett, K. (2008). Phonological priming in infancy. In Proceedings of the 30th Annual Meeting of the Cognitive Science SocietySociety (pp. 1273-1278). Washington, USA.

Mani, N., \& Plunkett, K. (2010). Twelve-month-olds know their cups from their keps and tups. Infancy, 15(5), 445-470. http://doi.org/10.1111/j.1532-7078.2009.00027.x

Mani, N., \& Plunkett, K. (2011a). Does size matter? Subsegmental cues to vowel mispronunciation detection. Journal of Child Language, 38(3), 606-627. http://doi.org/10.1017/S0305000910000243

Mani, N., \& Plunkett, K. (2011b). Phonological priming and cohort effects in toddlers. Cognition, 121(2), 196-206. http://doi.org/10.1016/j.cognition.2011.06.013

Marchman, V. A., \& Fernald, A. (2008). Speed of word recognition and vocabulary knowledge in infancy predict cognitive and language outcomes in later childhood. Developmental Science, 11(3), F9-16. http://doi.org/10.1111/j.1467-7687.2008.00671.x.Speed
Marchman, V. A., Fernald, A., \& Hurtado, N. (2009). How vocabulary size in two languages relates to efficiency in spoken word recognition by young Spanish-English bilinguals. Journal of Child Language, 37(4), 817-840. http://doi.org/10.1017/S0305000909990055

Maris, E., \& Oostenveld, R. (2007). Nonparametric statistical testing of EEG- and MEG-data. Journal of Neuroscience Methods, 164(1), 177-190. http://doi.org/10.1016/j.jneumeth.2007.03.024

Meints, K., \& Woodford, A. (2008). Lincoln Infant Lab Package 1.0: A new programme package for IPL, Preferential Listening, Habituation and Eyetracking. Retrieved from http://www.lincoln.ac.uk/psychology/babylab.htm

Mirman, D. (2014). Growth Curve Analysis and Visualization Using R. Chapman and Hall/CRC.

Mirman, D., Dixon, J. A., \& Magnuson, J. S. (2008). Statistical and computational models of the visual world paradigm: Growth curves and individual differences. Journal of Memory \& Language, 59(4), 475-494. http://doi.org/10.1016/j.jml.2007.11.006

Misra, M., Guo, T., Bobb, S. C., \& Kroll, J. F. (2012). When bilinguals choose a single word to speak: Electrophysiological evidence for inhibition of the native language. Journal of Memory and Language, 67(1), 224237. http://doi.org/10.1016/j.jml.2012.05.001

Mulak, K. E., Best, C. T., \& Tyler, M. (2013). Development of phonological constancy: 19-month-olds, but not 15-month-olds, identify words in a non-native regional accent. Child Development, 84(6), 2064-2078. http://doi.org/10.1111/cdev.12087.Development

Nazzi, T., Poltrock, S., \& Von Holzen, K. (2016). The developmental origins of the consonant bias in lexical processing. Current Directions in Psychological Science, 25(4), 291-296. http://doi.org/ $10.1177 / 0963721416655786$

Newman, R. S., Samuelson, L., \& Gupta, P. (2008). Learning novel neighbors: Distributed mappings help children and connectionist models, In Proceedings of the 30th Annual Meeting of the Cognitive Science Society (pp. 29-34). Mahwah, New Jersey.

Poarch, G. J., \& van Hell, J. G. (2012). Cross-language activation in children's speech production: Evidence from second language learners, bilinguals, and trilinguals. Journal of Experimental Child Psychology, 111(3), 419-438. http://doi.org/10.1016/j.jecp.2011.09.008

Ramon-Casas, M., \& Bosch, L. (2010). Are non-cognate words phonologically better specified than cognates in the early lexicon of bilingual children? Selected Proceedings of the 4th Conference on Laboratory Approaches to Spanish Phonology, 31-36.

Ramon-Casas, M., Swingley, D., Sebastian-Gallés, N., \& Bosch, L. (2009). Vowel categorization during word recognition in bilingual toddlers. Cognitive Psychology, 59(1), 96-121. http://doi.org/10.1016/j.cogpsych.2009.02.002

Rohde, A. (2001). The early bird catches the word: Bilingual preschool education in Germany - A psycholinguistic perspective. Društvena Istraživanja.

Ronjat, J. (1913). Le développement du langage observé chez un enfant bilingue. Paris: Champion. 
Schelletter, C. (2002). The effect of form similarity on bilingual children's lexical development. Bilingualism: Language and Cognition, 5(2), 93-107. http://doi.org/ 10.1017/S1366728902000214

Schwartz, A. I., Kroll, J. F., \& Diaz, M. (2007). Reading words in Spanish and English: Mapping orthography to phonology in two languages. Language and Cognitive Processes, 22(1), 106-129. http://doi.org/10.1080/01690960500463920

Singh, L. (2014). One World, Two Languages: Cross-Language Semantic Priming in Bilingual Toddlers. Child Development, 85(2), 755-766. http://doi.org/10.1111/cdev.12133

Storkel, H. L. (2004). Do children acquire dense neighborhoods? An investigation of similarity neighborhoods in lexical acquisition. Applied Psycholinguistics, 25(2), 201-221. http://doi.org/10.1017/S0142716404001109

Swingley, D. (2016). Two-year-olds interpret novel phonological neighbors as familiar words. Developmental Psychology, 52(7), 1011-1023. http://doi.org/10.1037/dev0000114

Swingley, D., \& Aslin, R. N. (2000). Spoken word recognition and lexical representation in very young children. Cognition, 76(2), 147-166. http://doi.org/ 10.1016/S0010-0277(00)00081-0

Swingley, D., \& Aslin, R. N. (2002). Lexical neighborhoods and the word-form representations of 14-month-olds. Psychological Science, 13(5), 480-4.

Swingley, D., \& Aslin, R. N. (2007). Lexical competition in young children's word learning. Cogni- tive Psychology, 54(2), 99-132. http://doi.org/10.1016/ j.cogpsych.2006.05.001

Szagun, G., Stumper, B., \& Schramm, A. (2009). Fragebogen zur frühkindlichen Sprachentwicklung FRAKIS und FRAKIS-K (Kurzform). Frankfurt, Germany: Pearson Assessment.

Von Holzen, K., \& Mani, N. (2012). Language nonselective lexical access in bilingual toddlers. Journal of Experimental Child Psychology, 113, 569-586. http://doi.org/10.1016/j.jecp.2011.02.002

Von Holzen, K., \& Mani, N. (2014). Bilinguals implicitly name objects in both their languages: An ERP study. Frontiers in Psychology, 5 (DEC), 1-12. http://doi.org/10.3389/fpsyg.2014.01415

Weber, A., \& Cutler, A. (2006). First-language phonotactics in second-language listening, (January), 597-607. http://doi.org/10.1121/1.2141003

Wewalaarachchi, T. D., Wong, L. H., \& Singh, L. (2017). Vowels, consonants, and lexical tones: Sensitivity to phonological variation in monolingual Mandarin and bilingual English - Mandarin toddlers. Journal of Experimental Child Psychology, 159, 16-33. http://doi.org/10.1016/j.jecp.2017.01. 009

White, K. S., \& Morgan, J. L. (2008). Sub-segmental detail in early lexical representations. Journal of Memory and Language, 52(1), 114-132. http://doi.org/ 10.1016/j.jml.2008.03.001 